\title{
Molecular dynamics simulations of the electrical double layer on smectite surfaces contacting concentrated mixed electrolyte $\left(\mathrm{NaCl}-\mathrm{CaCl}_{2}\right)$ solutions
}

\author{
Ian C. Bourg* \& Garrison Sposito
}

Geochemistry Department, Earth Sciences Division, Lawrence Berkeley National Lab, Berkeley CA, USA

\begin{abstract}
We report new molecular dynamics results elucidating the structure of the electrical double layer (EDL) on smectite surfaces contacting mixed $\mathrm{NaCl}-\mathrm{CaCl}_{2}$ electrolyte solutions in the range of concentrations relevant to pore waters in geologic repositories for $\mathrm{CO}_{2}$ or high-level radioactive waste $\left(0.34\right.$ to $\left.1.83 \mathrm{~mol}_{\mathrm{c}} \mathrm{dm}^{-3}\right)$. Our results confirm the existence of three distinct ion adsorption planes (0-, $\beta$-, and d-planes), often assumed in EDL models, but with two important qualifications: (1) the location of the $\beta$ - and dplanes are independent of ionic strength or ion type and (2) "indifferent electrolyte" ions can occupy all three planes. Charge inversion occurred in the diffuse ion swarm because of the affinity of the clay surface for $\mathrm{CaCl}^{+}$ion pairs. Therefore, at concentrations $\geq 0.34$ $\mathrm{mol}_{\mathrm{c}} \mathrm{dm}^{-3}$, properties arising from long-range electrostatics at interfaces (electrophoresis, electro-osmosis, co-ion exclusion, colloidal aggregation) will not be correctly predicted by most EDL models. Co-ion exclusion, typically neglected by surface speciation models, balanced a large part of the clay mineral structural charge in the more concentrated solutions. Water molecules and ions diffused relatively rapidly even in the first statistical water monolayer, contradicting reports of rigid "ice-like" structures for water on clay mineral surfaces.
\end{abstract}

Keywords: clay mineral, smectite, montmorillonite, adsorption, electrical double layer, triple layer model, surface complexation model, surface complex, diffusion, molecular dynamics simulation.

*Corresponding author: icbourg@lbl.gov; Tel: (+1) 510-486-7393; Lawrence Berkeley National Lab, 1 Cyclotron Road MS 90-1116, Berkeley, CA 94720-8126, USA. 


\section{Introduction}

The electrical double layer (EDL) on charged solid surfaces in contact with an aqueous electrolyte solution containing small inorganic ions is known to consist of three kinds of adsorbate species: inner-sphere surface complexes (ISSC), outer-sphere surface complexes (OSSC), and diffuse swarm (DS) species [1,2]. This view is adopted, for example, as the molecular basis for the widely-applied triple-layer model (TLM [3-5]), on which the distribution of ions near a charged planar solid surface is calculated under a set of simplifying assumptions that include assigning all ISSCs to a plane at the solid surface (0-plane), all OSSCs to a second plane lying farther into the aqueous phase ( $\beta$ plane), and all DS species to a region lying beyond a third plane farther out than the $\beta$ plane (d-plane) (Fig. 1). Computational and physical closure in the TLM is achieved as in other surface speciation models, by invoking charge-potential relationships in which the electrostatic potential drops between the 0 - and $\beta$ - and the $\beta$ - and d-planes are modeled with the help of two capacitance factors, while that across the diffuse swarm is modeled with the well-known Poisson-Boltzmann equation.

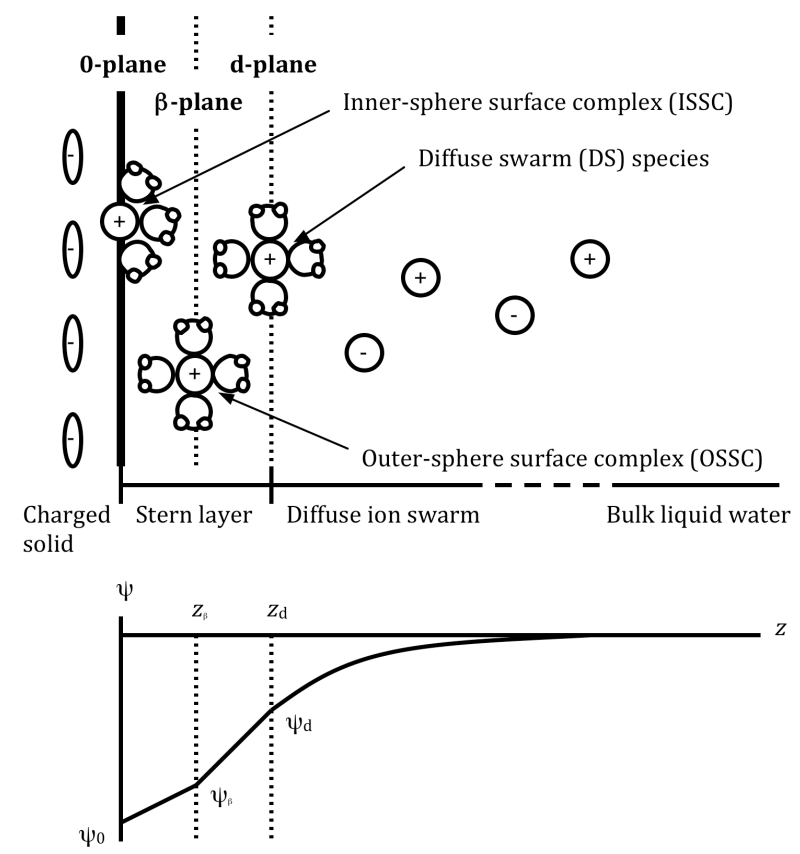

Figure 1. Conceptual model of EDL structure (top) and electrostatic potential $\psi(z)$ (bottom, relative to a reference state in the bulk liquid) as a function of distance from a negatively charged surface according to the TLM $[1,4]$. On the TLM, the electrostatic potential drop in the Stern 
layer is modeled by analogy with two capacitors: $\psi_{\beta}-\psi_{0}=-\sigma_{0} / C_{1}$ and $\psi_{\mathrm{d}}-\psi_{\mathrm{p}}=\sigma_{\mathrm{d}} / C_{2}$, where $\sigma_{0}$ is the surface charge density (solid structural charge plus the charge of all species adsorbed in the 0 plane), $\sigma_{\mathrm{d}}$ is the excess charge in the diffuse layer, $\psi_{0}, \psi_{\mathrm{s}}$, and $\psi_{\mathrm{d}}$ are the electrostatic potentials at the 0-, $\beta$-, and d-planes, and $C_{1}$ and $C_{2}$ are the capacitances of the space between the 0 - and $\beta$ planes and between the $\beta$ - and d-planes, respectively. The electrostatic potential in the diffuse ion swarm is modeled using the Poisson-Boltzmann equation for a flat surface: $d^{2} \psi / d z^{2}=-\left(\varepsilon_{0} \varepsilon_{\mathrm{w}}\right)^{-1}$ $\Sigma_{i}\left[Z_{i} F c_{i 0} \exp \left(-Z_{i} F \psi / R T\right)\right]$, where $\varepsilon_{0}$ is the permittivity of vacuum, $\varepsilon_{\mathrm{w}}$ is the dielectric constant of water, $Z_{i}$ and $c_{i 0}$ are the valence and bulk aqueous concentration of species $i, F$ is the Faraday constant, $R$ is the molar gas constant, and $T$ is absolute temperature.

Inferences about EDL surface speciation and molecular structure from experimental data on proton and ion adsorption [6,7,8], salt filtration efficiency [9], second harmonic generation [10], electrophoretic mobility [11], or interparticle forces [12] are necessarily sensitive to simplifying EDL model assumptions such as those just described for the TLM [13-16]. Models of the EDL that approximate liquid water as a uniform dielectric continuum (such as the Poisson-Boltzmann equation [17,18], hypernetted chain theory $[19,20]$, or the primitive model $[18,21])$ inherently cannot describe surface complexes $[17,18]$. Spectroscopic methods that probe the local molecular environment of "reporter atoms" (for example, nuclear magnetic resonance (NMR) [22,23] or x-ray absorption spectroscopy (XAS) [24,25]) have shown that adsorbed inorganic ions can adopt several different configurations that include both fully- and partly-solvated species. Resonant anomalous X-ray reflectivity (RAXR) studies, which probe solute concentration as a function of distance from a planar surface, have confirmed that EDL ions can adsorb simultaneously in both ISSCs and OSSCs [26-30]. However, spectroscopic techniques have not yet succeeded in simultaneously detecting all three adsorbate species to show that they can coexist in the same nanoscale interfacial region, nor have they been able to resolve their fine structure.

The present state of affairs in theory and experiment thus leaves open some key fundamental questions about EDL structure: Are there three - and only three-welldefined adsorption planes [27,29,31]? Are the typical "indifferent electrolyte" ions [1], such as $\mathrm{Na}^{+}$and $\mathrm{Cl}^{-}$, excluded from the 0 -plane [5] or from both the 0 - and $\beta$-planes [13]? Can the capacitance factors applied to model the region between the 0 - and d-planes 
$[8,21]$ and the model binding constants describing the adsorption of background electrolyte ions in the $\beta$-plane [32] be predicted instead of inferred from experimental data as fitting parameters, often poorly constrained [13,16,33]? And finally, the abiding question, how accurately does the Poisson-Boltzmann equation used in all EDL models predict ion distributions and electrostatic potentials in the diffuse swarm $[21,34]$ ?

For more than a decade, molecular dynamics (MD) and Monte Carlo (MC) simulations have provided insight into the behavior of water and ions near flat charged surfaces [2,18,35-54]. In particular, these simulations have confirmed that ions confined between planar charged surfaces do form ISSC, OSSC, and diffuse swarm species [35] in agreement with most EDL models. However, few simulations have investigated the molecular structure of the EDL in water films sufficiently thick ( $>4 \mathrm{~nm}[42])$ to probe the transition from adsorbed water to bulk liquid water [39,51,52]. Of the few studies that have done this, most used simulation times too short $(<2 \mathrm{~ns})$ to allow counterions to exchange extensively between ISSC, OSSC, DS, and bulk electrolyte species. To our knowledge, only Tournassat et al. [52] have carried out a long (10 ns) MD simulation of a full EDL on a planar charged surface. These authors simulated the structure of a $0.1 \mathrm{~mol}$ $\mathrm{dm}^{-3} \mathrm{NaCl}$ solution near a negatively-charged Na-smectite basal-plane surface. Although the $\mathrm{Na}^{+}$and $\mathrm{Cl}^{-}$distributions they found were qualitatively consistent with the TLM, there were significant quantitative differences from model predictions. For example, the TLM overestimated anion exclusion from the clay surface by about $50 \%$.

Here we present the results of MD simulations that extend the work of Tournassat et al. [52] to a mixed electrolyte of environmental importance $\left(\mathrm{NaCl} / \mathrm{CaCl}_{2}\right)$, a broad range of electrolyte charge concentration ( 0.34 to $1.83 \mathrm{~mol}_{\mathrm{c}} \mathrm{dm}^{-3}$ ), and much longer simulation timescales (50 ns). Following Tournassat et al. [52], we focus on smectites because these ubiquitous clay mineral nanoparticles play important roles in soil chemistry [55,56], soil mechanics [57], fault friction [58,59], materials chemistry [60], landfill and contaminated site isolation [61,62], high-level radioactive waste storage [63,64], $\mathrm{CO}_{2}$ sequestration $[65,66]$, and gas hydrate stability in marine sediments $[67,68]$. Their adsorption properties for small inorganic ions have been extensively studied using macroscopic [55,56,69], spectroscopic [24,25], and MD simulation techniques [18,35,37,45,49,52]. Furthermore, smectites are isostructural with the well-crystallized micas used in surface 
force [12,70], x-ray reflectivity [26,27], and MD and MC simulation studies of EDL properties [38,44,51]. Our choice of mixed electrolyte solution (hereafter termed "brine") allows comparison of the adsorption behavior of two major environmental cations, and our range of charge concentration $\left(0.34\right.$ to $\left.1.83 \mathrm{~mol}_{\mathrm{c}} \mathrm{dm}^{-3}\right)$ covers that in high-level radioactive waste repositories ( 0.07 to $0.6 \mathrm{~mol}_{\mathrm{c}} \mathrm{dm}^{-3}$ [71-73]), seawater (0.6 $\mathrm{mol}_{\mathrm{c}} \mathrm{dm}^{-3}[74]$ ), methane hydrates in ocean sediments ( 0.6 to $\left.4.1 \mathrm{~mol}_{\mathrm{c}} \mathrm{dm}^{-3}[75,76]\right)$, and saline aquifers being considered for $\mathrm{CO}_{2}$ sequestration (0.7 to $2.2 \mathrm{~mol}_{\mathrm{c}} \mathrm{dm}^{-3}$ [65,77-79]). Finally, our long simulation times (50 ns) allow a more stringent evaluation of current EDL models such as the TLM.

\section{Molecular dynamics simulation methodology}

Molecular dynamics simulations ( $50 \mathrm{~ns}$, preceded by $1.2 \mathrm{~ns}$ of equilibration at $298 \mathrm{~K}$ ) of $\mathrm{NaCl} / \mathrm{CaCl}_{2}$ brine confined in a $58 \AA$-wide nanopore between smectite basal surfaces were carried out in the microcanonical (NVE) ensemble with the program MOLDY 3.6 [80]. Our periodically replicated simulation cell contained one lamellum of Otay-type montmorillonite composed of 18 unit cells (dimension $30.8928 \times 26.9932 \AA$ in the $x y$ plane) and a brine-filled nanopore containing 1620 water molecules (Fig. 2). The width of our simulated nanopore was chosen such that roughly one-third of all the water molecules in the system would behave as they do in bulk liquid water [50]. Our clay mineral structure was the same as that used by Bourg and Sposito [54]: montmorillonite atomic coordinates were fixed on the basis of the pyrophyllite structure of Bickmore et al. [81], and the negative structural charge of our clay lamella $\left(1.2 \mathrm{~mol}_{\mathrm{c}} \mathrm{kg}^{-1}\right)$ resulted from 16 isomorphic substitutions of $\mathrm{Al}^{3+}$ by $\mathrm{Mg}^{2+}$ [average unit cell formula $\left.\mathrm{Si}_{8}\left(\mathrm{Al}_{3.111} \mathrm{Mg}_{0.889}\right) \mathrm{O}_{20}(\mathrm{OH})_{4}\right]$ randomly scattered in the octahedral sheet [82] under the constraint that substitutions could not occur in adjacent OH-sharing octahedral sites [83]. Simulations were carried out for $\mathrm{Na} / \mathrm{Ca} / \mathrm{Cl}$ compositions of $12 / 6 / 8,16 / 8 / 16,24 / 12 / 32$, and $32 / 16 / 48$ atoms per simulation cell, resulting in bulk chloride concentrations of 0.34 , $0.67,1.25$ and $1.83 \mathrm{~mol} \mathrm{dm}^{-3}$. Prior to our simulations, cell $z$ dimensions were determined by equilibrating each system for $200 \mathrm{ps}$ at $298 \mathrm{~K}$ and constant volume, then for $400 \mathrm{ps}$ at $298 \mathrm{~K}$ and constant gauge pressure $P_{\mathrm{z}}=0$ ( $N V E$ and $N P_{z} E$ ensemble simulations, respectively, with molecular velocities scaled to $298 \mathrm{~K}$ every $10 \mathrm{ps})$. 
Average $z$ cell dimensions during the last $300 \mathrm{ps}$ of this equilibration were 66.65, 67.09, 67.59 and $68.17 \AA$ for simulations with electrolyte concentrations of $0.34,0.67,1.25$ and $1.83 \mathrm{~mol}_{\mathrm{c}} \mathrm{dm}^{-3}$, respectively. Total energy conservation during our $50 \mathrm{~ns}$ simulations was better than $99.99 \%$. Long-range Coulomb interactions were treated by Ewald summation with parameters chosen to yield an Ewald sum accuracy of $99.99 \%$.

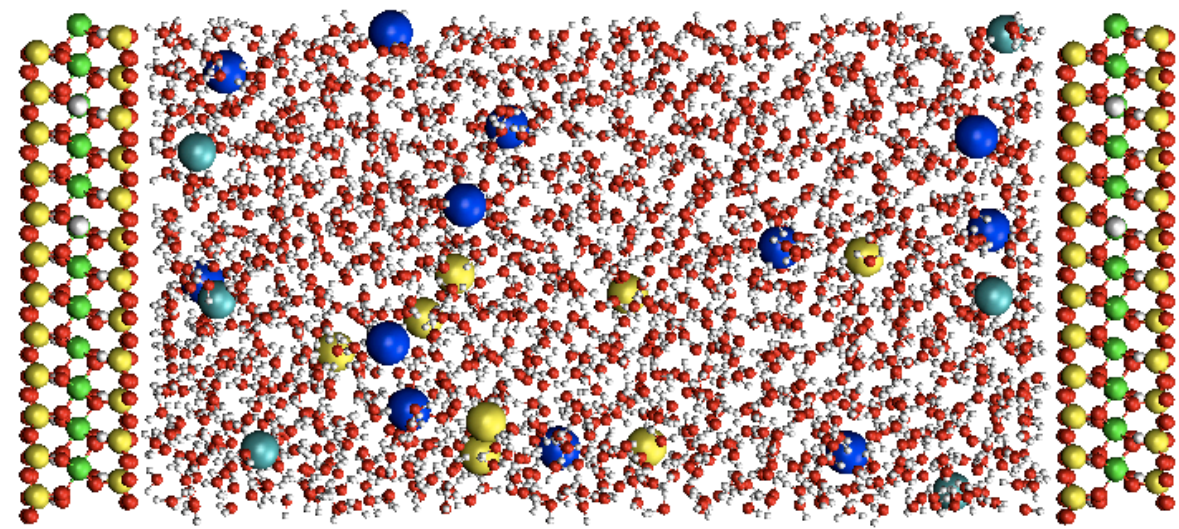

Figure 2. Snapshot of our MD simulation cell showing a $0.34 \mathrm{~mol}_{\mathrm{c}} \mathrm{dm}^{-3}$ brine confined in a $58 \AA$ A wide nanopore between parallel smectite clay surfaces, with $\mathrm{Na}$ (dark blue), $\mathrm{Ca}$ (light blue), $\mathrm{Cl}$ (yellow), water $\mathrm{O}$ (red) and water $\mathrm{H}$ (white) atoms in the interlayer and $\mathrm{Si}$ (yellow), $\mathrm{Al}$ (green), $\mathrm{Mg}$ (white), $\mathrm{O}$ (red) and $\mathrm{H}$ (white) atoms in the clay mineral structure. The upper clay surface is a periodic image of the lower clay surface.

Molecular dynamics simulations are necessarily sensitive to the choice of interatomic potentials, the main input of such simulations [35,44,52]. In the present study, we used the extended simple point charge (SPC/E) water model [84], the Smith-Dang solute-water interaction potentials for $\mathrm{Na}^{+}$and $\mathrm{Cl}^{-}$[85], the Åqvist solute-water potential for $\mathrm{Ca}^{2+}$ [86], and the CLAYFF model for smectite [87] (Table 1). These interatomic potentials are known to predict accurately the molecular structure [88], static dielectric constant [89], and self-diffusion coefficient [85] in bulk liquid water; the solvation structure [85], diffusion coefficients [90], and isotopic mass dependence of the diffusion coefficients [91] of ionic solutes in liquid water; $\mathrm{NaCl}$ ion pairing and solubility in ambient water [92]; and the structure and diffusion coefficients of water and solutes in Namontmorillonite interlayer nanopores [54]. We also verified that the interatomic 
potentials in Table 1 quite accurately predict the observed mass densities of $\mathrm{NaCl} / \mathrm{CaCl}$ brines at 298 K [93] (Fig. EA1 of the Electronic Annex).

\section{Structure of the Electrical Double Layer}

\subsection{Interfacial water structure}

For each simulated system, we calculated the molar density of $\mathrm{H}_{2} \mathrm{O}, \mathrm{Na}^{+}, \mathrm{Ca}^{2+}$, and $\mathrm{Cl}^{-}$as a function of distance from the mid-lamella plane (Fig. 3). Our results show that the pronounced water density layering at the mineral surface dissipates within about $9 \AA$ (three times the diameter of a water molecule), in agreement with previous studies of water on flat solid surfaces $[30,37,38,94,95]$. The location of the Gibbs dividing surface of water in our simulations $\left(z_{\text {surface }}=4.40 \pm 0.06 \AA\right)$ is close to that expected for the mineral basal plane from macroscopic estimates of the thickness of montmorillonite lamellae $\left(d_{\text {mont }}=9.4 \pm 0.1 \AA[96]\right.$, which yield $\left.z_{\text {surface }}=4.7 \pm 0.05 \AA\right)$ or from the clay mineral atomic structure $\left(z_{\text {surface }}=4.6 \pm 0.05 \AA\right.$, the sum of the average $z$ coordinate of basal surface $\mathrm{O}$ atoms, $3.2 \AA$, and the radius of the $\mathrm{O}$ atom, $1.4 \AA[52])$. We infer from this near-congruence of the Gibbs dividing surface and the geometric mineral surface that the water density near the latter must be equal to or slightly greater than the density of bulk liquid water.

The $z$ coordinates of the first shoulder and first four peaks of the water density profile are reported in Table 2 along with the numbers of water molecules per unit cell corresponding to each of these features, as calculated by integrating the density profile between minima. For ease of comparison with previous studies of clay-water interfaces, $z$ coordinates are sometimes expressed hereafter relative to the average height of surface $\mathrm{O}$ atoms as $z^{*}=z-3.2 \AA$. The main water density peak is located at $z^{*}=2.7 \pm 0.05 \AA$, in agreement with the values for water electron density on mica as measured by X-ray reflectivity $(2.5 \pm 0.2 \AA[30])$ and for water $\mathrm{O}$ atom density on smectite and mica predicted by other MD simulations (2.6 to $2.75 \AA[37,44,52,53])$. Snapshots of our simulation cells confirm previous assignments [44,53] of the first shoulder and first two peaks of the water density profile to water molecules that form hydrogen bonds with two $\left(z^{*} \approx 1.8 \AA\right)$, one $\left(z^{*}=2.7 \AA\right)$, or no surface $\mathrm{O}$ atoms $\left(z^{*}=4.0 \AA\right)$, respectively (Fig. 4$)$. 

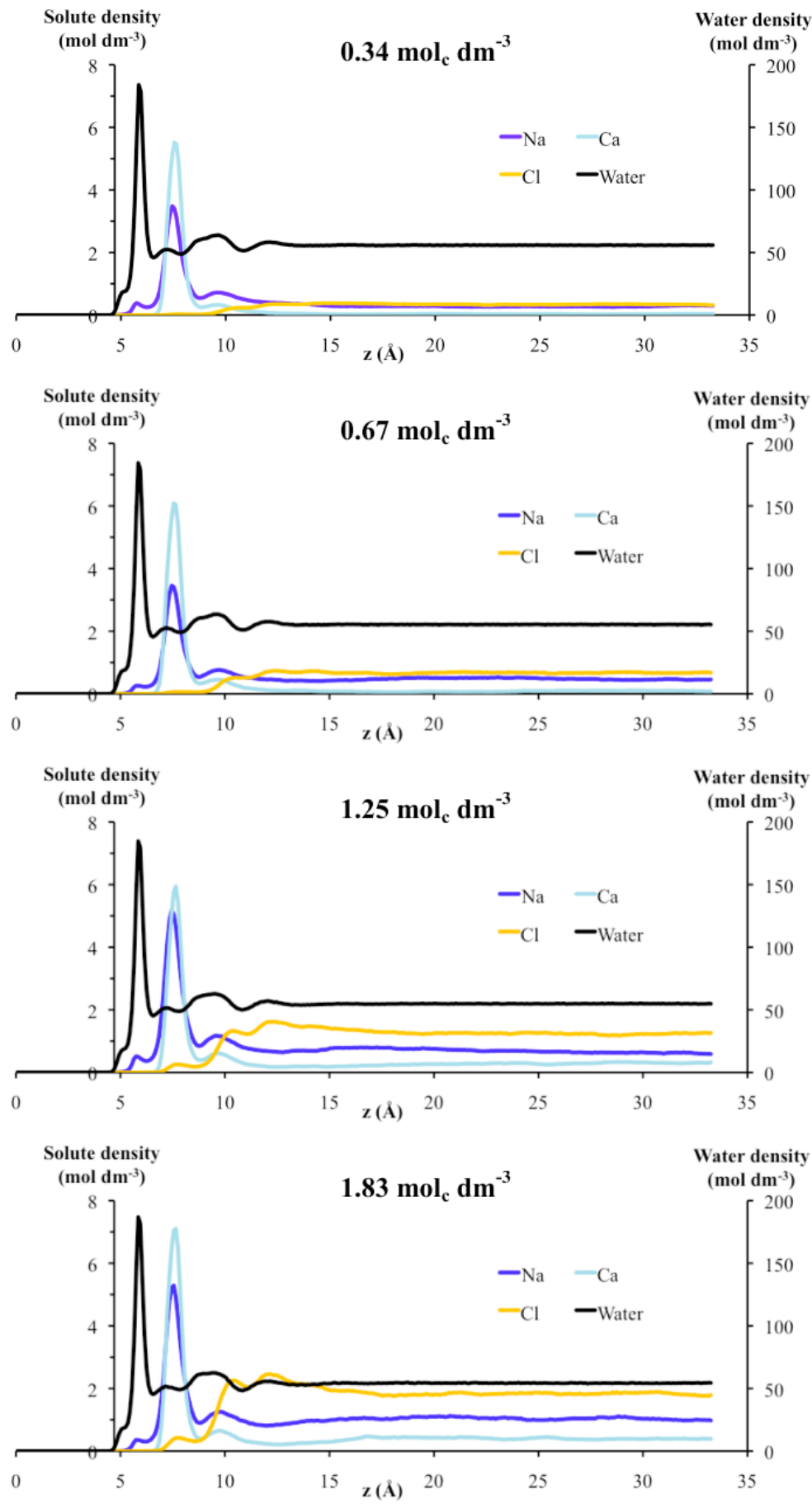

Figure 3. Average density ( $\mathrm{mol} \mathrm{dm}^{-3}$ ) of water (black), $\mathrm{Na}$ (dark blue), $\mathrm{Ca}$ (light blue) and $\mathrm{Cl}$ (orange) as a function of distance from the mid-plane of the smectite lamella at brine concentrations of $0.34,0.67,1.25$ and $1.83 \mathrm{~mol}_{\mathrm{c}} \mathrm{dm}^{-3}$. The vertical axis on the left side is drawn at the approximate location of the clay-water interface ( $z=4.7 \AA$; see section 3.1$)$. Water density was calculated using $\mathrm{H}_{2} \mathrm{O}$ center of mass coordinates. 


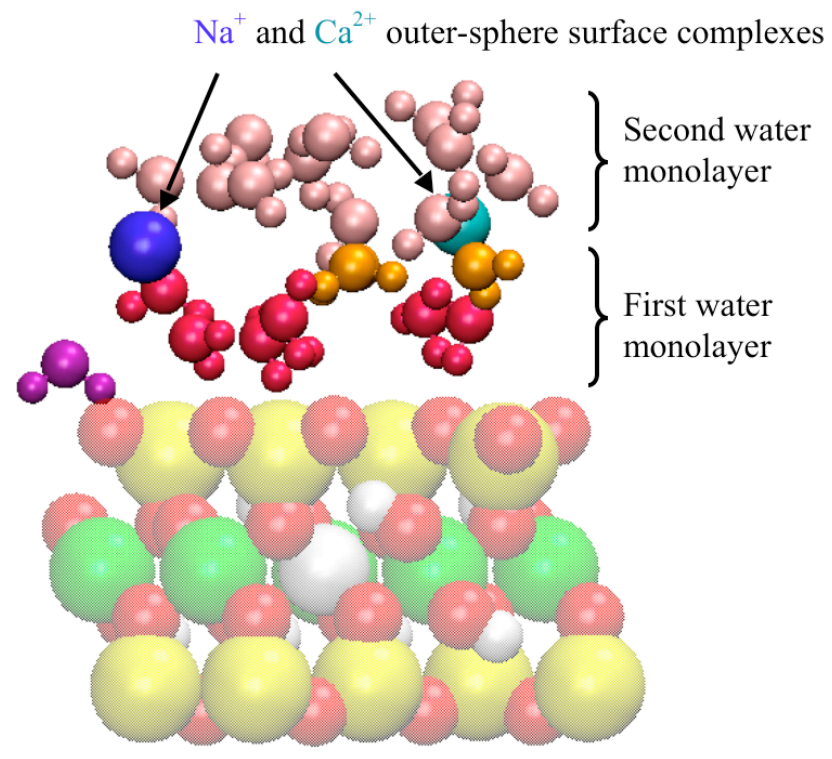

Figure 4. Snapshot of the first two statistical water monolayers above a $10 \AA \times 10 \AA$ portion of the montmorillonite lamella at $0.34 \mathrm{~mol}_{\mathrm{c}} \mathrm{dm}^{-3}$. Water molecules from the first shoulder and first three peaks of the water density profile are shown in violet, magenta, orange, and pink, respectively. All other atoms are colored as in Fig. 2.

The first shoulder and first two peaks of the water density profile $\left(z^{*}=1.4\right.$ to $\left.4.6 \AA\right)$ contain 5.1 water molecules per unit cell and are about as wide as a water molecule; thus, they form one statistical water monolayer (the one-layer hydrate of Na-montmorillonite, for example, contains about 5 water molecules per unit cell and exhibits an interlayer spacing of about $3 \AA[47,54])$. The third peak of the water density profile $\left(z^{*}=4.6\right.$ to 7.6 $\AA$ ) contains 4.8 water molecules per unit cell and thus forms a second statistical water monolayer. These water density profiles near the clay surface are essentially unaffected by electrolyte concentration (Fig. 3; Table 2) as expected from previous statistical mechanical calculations [97] and MD simulations [36].

\subsection{Counterion adsorption}

Cation density profiles near the clay mineral surface (Fig. 3) show that $\mathrm{Na}^{+}$and $\mathrm{Ca}^{2+}$ adsorb as ISSC (observed only for $\mathrm{Na}^{+}$), OSSC, and DS species. Our $\mathrm{Na}^{+}$density profile 
at $0.34 \mathrm{~mol}_{\mathrm{c}} \mathrm{dm}^{-3}$ is similar to that obtained by Tournassat et al. [52] in their MD simulation of a $0.1 \mathrm{~mol} \mathrm{dm}^{-3} \mathrm{NaCl}$ solution on a montmorillonite basal plane. The density maximum corresponding to OSSC coordination is identified hereafter with the TLM $\beta$-plane, whereas the minimum between OSSC and DS peaks is identified with the TLM d-plane (the plane beyond which DS species adsorb). Our simulations fully confirm the existence of three counterion adsorption planes $(0-, \beta-$, and d-planes $)$ and the co-occurrence of $\mathrm{Na}^{+}$and $\mathrm{Ca}^{2+}$ in the $\beta$ - and d-planes, in agreement with the TLM hypotheses (Fig. 1). Our results also show that so-called "indifferent electrolyte" ions can access all three adsorption planes, contrary to the TLM hypothesis that these ions cannot access the 0-plane [5], but consistent with the known ISSC formation by indifferent electrolyte ions on rutile [6,39], and with all-atom theoretical calculations [98]. Finally, our results confirm that $0-, \beta$-, and d-plane coordinates are invariant with changing ionic strength, as is generally assumed in surface speciation models.

Our results on the $z$ coordinates of cation density features (Table 2) show that the $\beta$ and d-plane coordinates are essentially independent of the type of counterion $\left(z_{\beta} *=4.35\right.$ $\pm 0.10 \AA ; z_{\mathrm{d}}{ }^{*}=5.65 \pm 0.10 \AA$ ). The $\beta$-plane coordinate of $\mathrm{Na}^{+}$and $\mathrm{Ca}^{2+}$ is identical within imprecision to that of the $\mathrm{Cl}^{-}$OSSCs in our simulations $\left(z_{\beta}^{*}=4.55 \pm 0.10 \AA \AA\right.$; Table $2)$ and to that of divalent cation OSSCs on mica as measured by X-ray reflectivity $\left(z_{\beta}^{*}=\right.$ $4.52 \pm 0.24 \AA$ for $\mathrm{Sr}^{2+}$ [26], with similar values for $\mathrm{Cu}^{2+}, \mathrm{Zn}^{2+}, \mathrm{Hg}^{2+}$, and $\mathrm{Pb}^{2+}$ [27]). Collectively, these results suggest strongly that the location of the $\beta$-plane is independent of the type of electrolyte, which conflicts with recent models of adsorption postulating that the $\beta$-plane coordinate is equal to a surface-specific constant plus the hydrated or crystal radius of the adsorptive ion $[7,8]$.

Although the $z$-coordinates of OSSCs are essentially independent of ion type, our simulations as well as other studies indicate that the same is not true of ISSCs. Park et al. [26] showed that $\mathrm{Sr}^{2+}$ ISSCs lie more closely to the basal surface than do $\mathrm{Rb}^{+}$ISSCs $\left(z^{*}=\right.$ $1.26 \pm 0.22$ and $2.33 \pm 0.10 \AA$ for $\mathrm{Sr}^{2+}$ and $\mathrm{Rb}^{+}$). Lee et al. [27] confirmed this speciesdependence of $z$-coordinates for and a range of cationic ISSCs $\left(\mathrm{K}^{+}, \mathrm{Cs}^{+}, \mathrm{Cu}^{2+}, \mathrm{Zn}^{2+}, \mathrm{Hg}^{2+}\right.$, $\mathrm{Pb}^{2+}, \mathrm{Ba}^{2+}$ ) on mica. In our simulations, $\mathrm{Na}^{+}$ISSCs lie farther from the basal surface than any of the cations investigated by Park et al. [26] and Lee et al. [27] $\left(z^{*}=2.6 \pm 0.05\right)$. 
Predota et al. [39] found similarly that the $z$-coordinates of ISSCs on rutile vary with the type of ion. This behavior is inconsistent with the molecular hypotheses of the TLM.

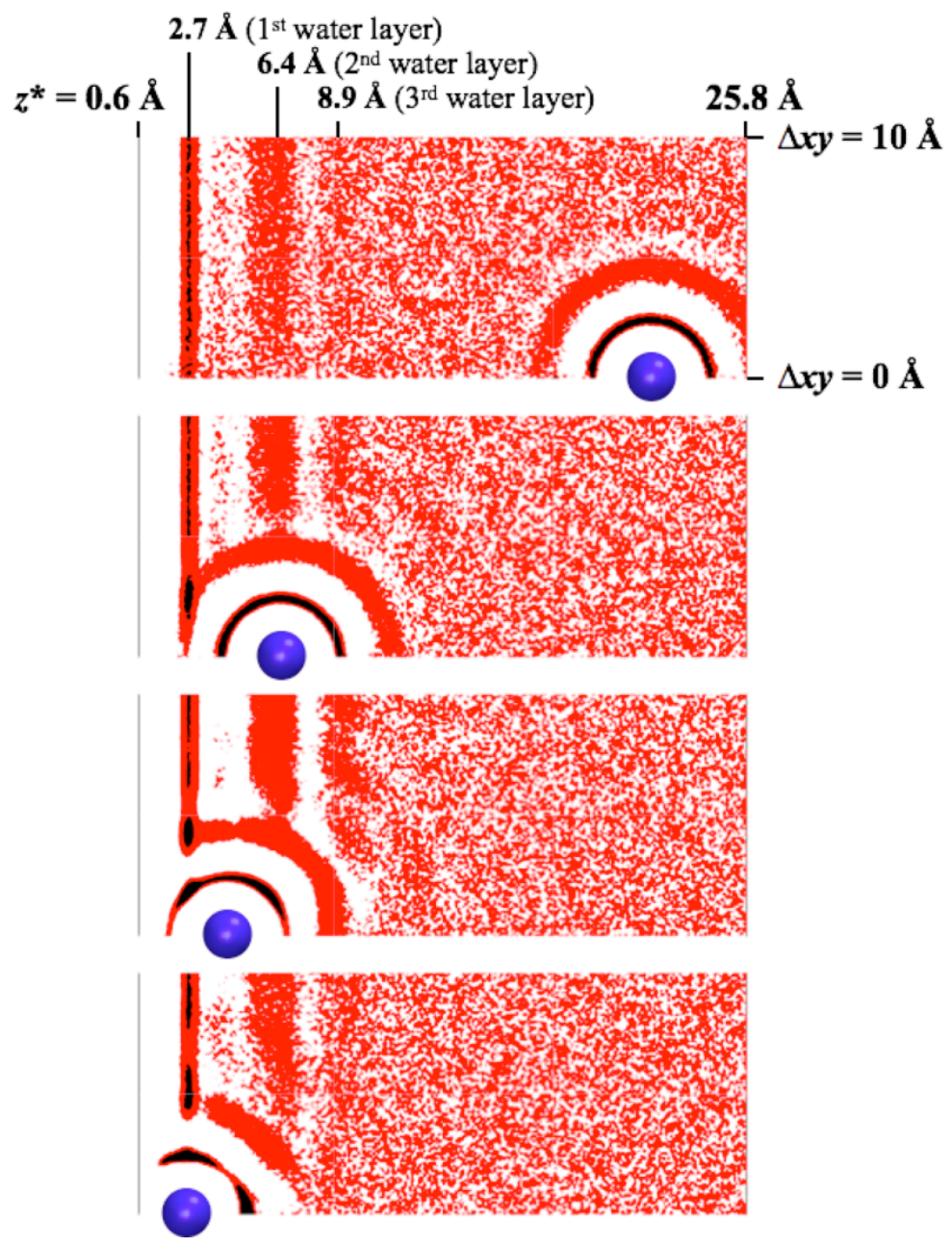

Figure 5. Water density map near $\mathrm{Na}^{+}$ions located (from upper to lower panel) in bulk liquid water $\left(z^{*}=21.8 \pm 0.1 \AA\right)$, in the diffuse ion swarm $\left(z^{*}=6.5 \pm 0.1 \AA\right)$, and at OSSC $\left(z^{*}=4.3 \pm\right.$ $0.1 \AA)$ and ISSC peak coordinates $\left(z^{*}=2.6 \pm 0.1 \AA\right)$ in our simulation at $0.34 \mathrm{~mol}_{\mathrm{c}} \mathrm{dm}^{-3}$. The horizontal coordinate is $z^{*}(\AA)$. The vertical coordinate, $\Delta x y(\AA)$, is the distance between the $\mathrm{Na}^{+}$ ion and the $\mathrm{H}_{2} \mathrm{O}$ center-of-mass in the plane normal to the $z$-axis. Colors indicate regions were water density is one to three times larger (red) or more than three times larger than in the bulk liquid (black).

To gain insight into the molecular-scale controls on the $z$ coordinates of ISSCs, OSSCs, and DS species, we calculated maps of average water density along directions 
parallel and normal to the mineral surface for ions located at selected distances from it.

Figure 5 shows four such water density maps for $\mathrm{Na}^{+}$ions located in the bulk liquid (Fig. 5a), in the diffuse swarm (Fig. 5b), and in OSSCs (Fig. 5c) or ISSCs (Fig. 5d). As seen in Figs. 5b-d, the $z$ coordinates of sodium DS, OSSC, and ISSC species optimize cation solvation by two, one, or zero full solvation shells, respectively, while minimizing the cation distance from the surface. Similar results were obtained for $\mathrm{Ca}^{2+}$. Evidently, cation density profiles near the surface reflect a competition between cation solvation and adsorption processes. The relative heights of ISSC, OSSC, and DS counterion peaks in Fig. 3 show that surface-counterion attraction readily overcomes the free energy cost of removing water from the second solvation shell of $\mathrm{Na}^{+}$and $\mathrm{Ca}^{2+}$ (as required to form an OSSC), but not the cost of removing water from their first solvation shell (as required to form an ISSC).

We note in passing that metal and mineral desolvation both have been invoked as possible rate-limiting steps of metal adsorption and precipitation reactions [46]. In the case of $\mathrm{Na}^{+}$or $\mathrm{Ca}^{2+}$, Fig. 5 c,d clearly shows that water interacts more strongly with the metals than with the surface. This finding is consistent with the evidence that the first stage of water adsorption on dry smectite is the solvation of exchangeable cations [99].

\subsection{Coion exclusion}

Chloride density profiles (Fig. 3; for a more detailed view see Fig. EA2 in the Electronic Annex) show that these coions are adsorbed as OSSCs and DS species. Our results on the $z$ coordinates of $\mathrm{Cl}^{-}$OSSCs are consistent with the TLM hypotheses and contradict suggestions that cationic and anionic OSSCs may lie in distinct $\beta$-planes [31]. The $z$ coordinate of the density minimum between $\mathrm{Cl}^{-}$OSSC and DS species is essentially identical to that of $\mathrm{Na}^{+}$and $\mathrm{Ca}^{2+}$ (Table 2), indicating that the location of the d-plane also is independent of ion type, as hypothesized in the TLM. However, the presence of coions in the $\beta$-plane in the absence of positively-charged surface functional groups contradicts the TLM and most other EDL models (a notable exception being the modified TLM of Robertson and Leckie [15]), but agrees with the results of all-atom theoretical calculations [98]. We hypothesize that the few $\mathrm{Cl}^{-}$OSSCs observed in our simulations may in fact be stabilized as positively-charged ion pairs, $\mathrm{CaCl}^{+}$. 
Two other features of the chloride density profiles in Fig. 3 are inconsistent with all extant EDL models: chloride concentration rises sharply beyond the d-plane $\left(z^{*}>5.5 \AA\right)$ to a peak or shoulder identified as DS1 in Table 2, and chloride is positively adsorbed in a broad region between $z^{*} \approx 7$ and $15 \AA$ (peaks DS2 and DS3 in Table 2). The first of these features was previously noted by Tournassat et al. [52] for a $0.1 \mathrm{~mol} \mathrm{dm}^{-3} \mathrm{NaCl}$ electrolyte contacting a montmorillonite basal surface. They pointed out that it contradicts the predictions of the Poisson-Boltzmann equation in the modified GouyChapman formulation. The second of these features, though to the best of our knowledge never previously reported in a MD simulation study, is nonetheless faintly discernible in the density profile of $\mathrm{Cl}^{-}$near a Na-montmorillonite surface calculated by Marry et al. [49].

To determine the origin of the $\mathrm{Cl}^{-}$density peaks, we mapped $\mathrm{Cl}^{-}$density in directions parallel and normal to the surface relative to $\mathrm{Ca}^{2+}$ and $\mathrm{Na}^{+}$OSSCs (Fig. 6). The resulting density maps show that $\mathrm{Cl}^{-}$ions accumulate preferentially near $\mathrm{Ca}^{2+}$ OSSCs as solventseparated ion pairs and to a lesser extent near $\mathrm{Na}^{+}$OSSCs as either contact or solventseparated ion pairs. The $z$ coordinates of $\mathrm{Cl}^{-}$ions in these chloride-metal ion pairs correspond to the region in which $\mathrm{Cl}^{-} \mathrm{DS} 1$ and DS2 species occur. Further calculations showed that $\mathrm{Cl}^{-} \mathrm{DS} 1$ and DS2 species adsorb preferentially above regions of the surface that contain a greater density of $\mathrm{Ca}^{2+}$ OSSCs (and, to a lesser extent, $\mathrm{Na}^{+}$OSSCs) than the surface as a whole. Thus, our results indicate that $\mathrm{Cl}^{-}$ions adsorb at the surface as metal-chloride ion pairs, which is consistent with previous findings, that ion pairs contribute significantly to both $\mathrm{Ca}$ adsorption on clay mineral surfaces $[69,100-103]$ and divalent metal adsorption on a range of substrates [104,105], as well as with the expectation that long-range electrostatic interactions should attract dipolar entities such as ion pairs (or water molecules $[106,107]$ ) to charged surfaces where their dipole moment can orient itself in response to the electrostatic potential gradient. Our results also are consistent with statistical mechanical calculations according to which ion-ion correlations should cause coion concentrations to rise more rapidly beyond the d-plane than predicted by the Poisson-Boltzmann equation, especially at high electrolyte concentrations or in the presence of multivalent counterions [20,34,108-110]. Finally, if ion-pair formation is viewed as a step toward nucleation, our results hint at a mechanism by which charged 
surfaces may promote heterogeneous nucleation of solid phases, with potential implications, for example, for carbonate precipitation in brine aquifers [65] or for controlled protein crystallization near charged interfaces [111].

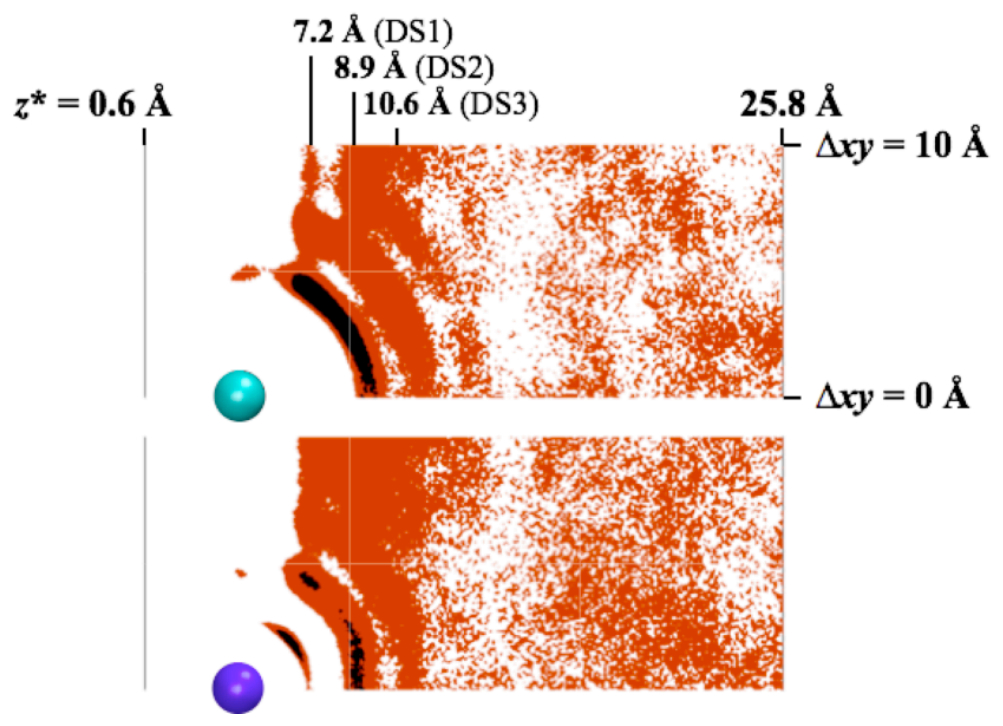

Figure 6. Same as Fig. 5 for $\mathrm{Cl}^{-}$density near $\mathrm{Ca}^{2+}$ (top) and $\mathrm{Na}^{+} \mathrm{OSSC}$ (bottom) at $1.83 \mathrm{~mol}_{\mathrm{c}}$ $\mathrm{dm}^{-3}$. Colors indicate regions were $\mathrm{Cl}^{-}$density is one to three times larger (ochre) or more than three times larger than in the bulk liquid (black).

Enhancement of the stability of metal-chloride ion pairs near charged surfaces can occur if the dielectric constant of interfacial water is lower than that of bulk liquid water $[112,113]$. To evaluate the importance of this phenomenon indirectly, we calculated Clion radial distribution functions $g(r)$ (where ion $=\mathrm{Na}^{+}, \mathrm{Ca}^{2+}$, or $\mathrm{Cl}^{-}$) at $1.83 \mathrm{~mol}_{\mathrm{c}} \mathrm{dm}^{-3}$ along directions parallel to the surface in the OSSC, DS1, DS2, and bulk liquid regions. Our results (Fig. 7) reveal that the population of metal-chloride ion pairs is enhanced (and that of chloride-chloride ion pairs is reduced) relative to their population in bulk liquid water only for $\mathrm{Cl}^{-}$ions located in the OSSC region. By inference, water located further than about $5 \AA$ from the surface has essentially the same dielectric constant as bulk liquid water, whereas the first one or two water monolayers on the clay surface have a lower dielectric constant. This finding is consistent with MD simulations of the quartz-water interface, wherein the dielectric constant was approximately 48 in the first statistical water monolayer, 74 in the second, and 80 beyond the second water monolayer [113]. 

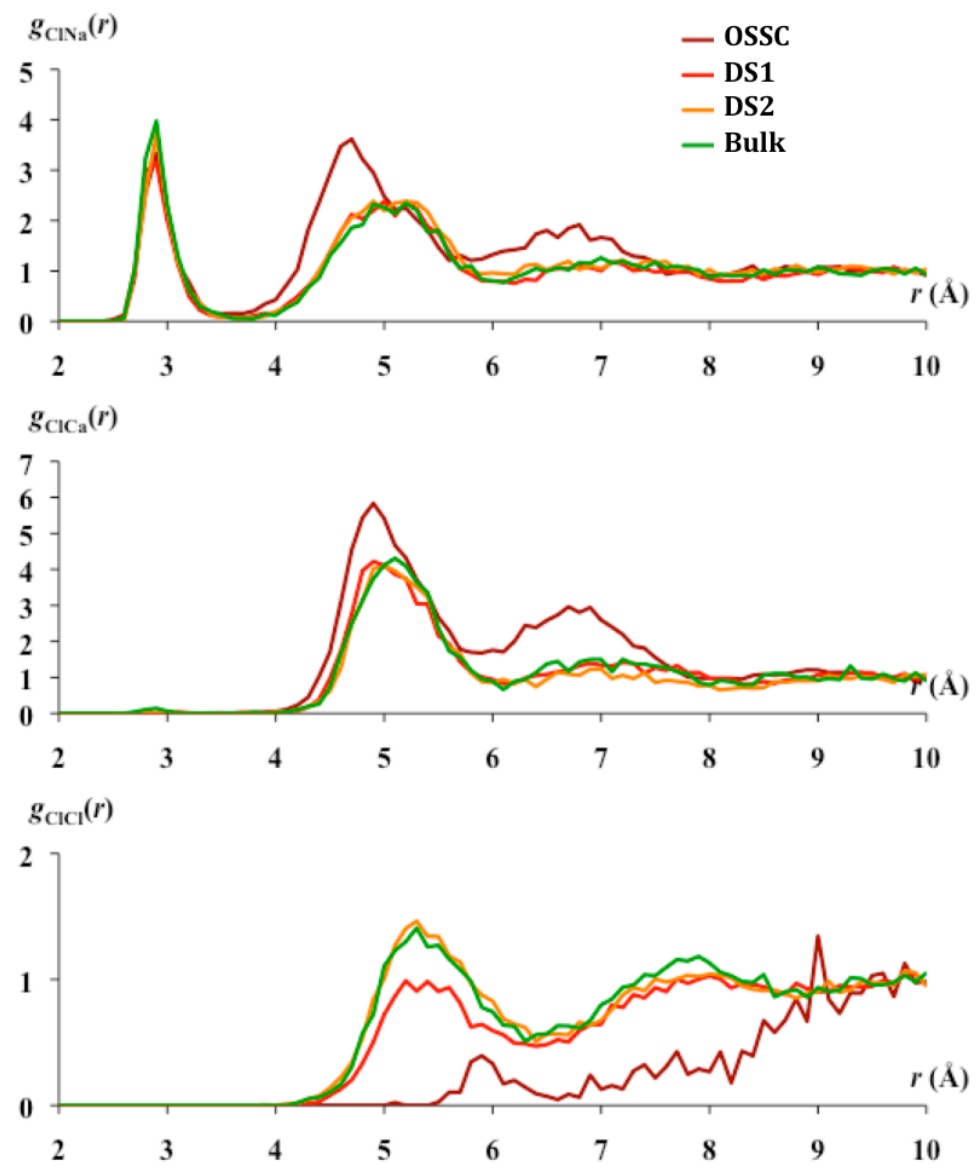

Figure 7. Plots of the $\mathrm{Cl}-\mathrm{Na}, \mathrm{Cl}-\mathrm{Ca}, \mathrm{Cl}-\mathrm{Cl}$ radial distribution functions calculated in directions parallel to the clay surface for ions located in the bulk liquid or at DS2, DS1, or OSSC coordinates $\left(z^{*}=21.8,8.9,7.2\right.$, or $\left.4.5 \pm 0.3 \AA\right)$ in our simulation at $1.83 \mathrm{~mol}_{\mathrm{c}} \mathrm{dm}^{-3}$.

\subsection{Surface charge screening}

The structural charge density $\left(\sigma_{\text {clay }}=-0.444 e\right.$ per unit cell on each surface in our simulations) is balanced in the EDL on length scales of nanometers by adsorbed cation charge density $q_{+}$minus adsorbed anion charge density $q_{-}$[1]:

$$
\sigma_{\text {clay }}+q_{+}-q_{-}=0
$$

The adsorbed cation (or anion) charge density equals the sum over all cations (or anions) of the magnitude of the valence $Z_{i}$ times the Gibbs surface excess $n_{i}{ }^{(\mathrm{w})}$ (adsorbed molecules per unit cell, customarily defined relative to the dividing surface of water). Gibbs surface excess values for $\mathrm{Na}^{+}, \mathrm{Ca}^{2+}$, and $\mathrm{Cl}^{-}$, calculated with the standard expression $n_{i}{ }^{(\mathrm{w})}=n_{i}-\left(n_{\mathrm{w}} x_{i} / x_{\mathrm{w}}\right)$ [1], where $n_{i}$ and $n_{\mathrm{w}}$ are the numbers of molecules of 
solute $i$ and water per unit cell on each surface in the interfacial region $(z<20 \AA)$ and $x_{i}$ and $x_{\mathrm{w}}$ are the mole fractions of $i$ and water in the bulk liquid $(z>20 \AA)$, are shown in Table 3 along with the percentage contribution of each species to balancing the structural charge. Evidently, as salinity increases, anion exclusion contributes increasingly to the overall charge balance at the mineral-water interface: at the highest salinity studied here, $42 \%$ of the structural charge is balanced by anion exclusion instead of cation adsorption.

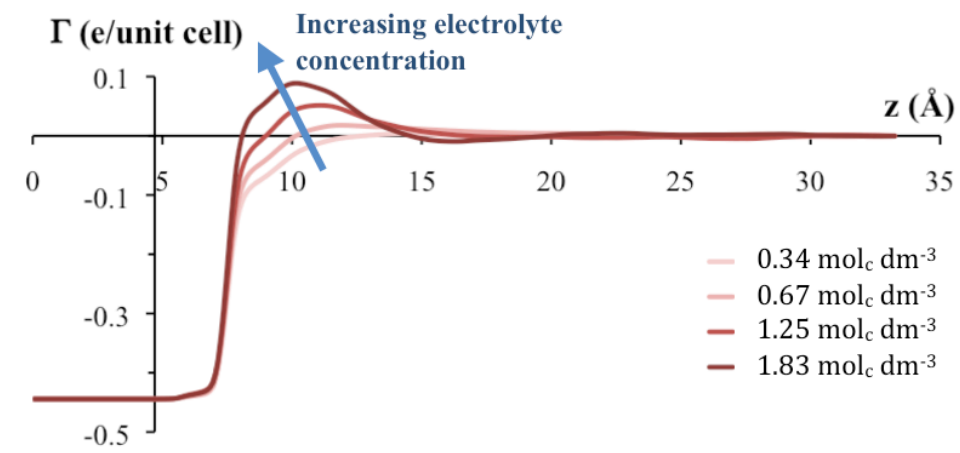

Figure 8. Screening function $\Gamma(z)$ (e per unit cell) plotted as a function of $z(\AA)$. At large $z$ values, $\Gamma(z)$ tends towards zero as adsorbed ions balance the negative structural charge of the clay particles. Positive values of $\Gamma(z)$ at $z>12 \AA$ indicate that the positive surface charge contributed by cation adsorption and anion exclusion in the first two or three water layers on the clay surface exceeds the negative structural charge of the clay particle.

In order to characterize the manner in which adsorbed ions balance the structural charge density $\sigma_{\text {clay }}$ as a function of distance from the clay surface, we define a "screening function" $\Gamma(z)=\sigma_{\text {clay }}+\int_{0}^{z} \sum_{i=N a, C a, C l} Z_{i} \rho_{i}(z) d z$, where $\rho_{i}(z)$ is the local density of species $i$. Essentially, $\Gamma(z)$ describes the apparent (screened) surface charge density as seen by a hypothetical probe located at coordinate $z$. At all electrolyte concentrations studied, the calculated $\Gamma(z)$ functions (Fig. 8) show that the negative structural charge is actually over-compensated by cation adsorption and anion exclusion within the first two or three water layers. Thus, to a probe located at $z>12 \AA$ at $0.34 \mathrm{~mol}_{\mathrm{c}} \mathrm{dm}^{-3}$ or $z>8 \AA$ at $1.83 \mathrm{~mol}_{\mathrm{c}} \mathrm{dm}^{-3}$, the mineral surface would appear to be positively charged. This behavior is inconsistent with the TLM and other surface speciation models, as they invariably 
predict that $\Gamma(z)$ has the same sign as $\sigma_{0}$ throughout the EDL in the presence of an indifferent electrolyte. This well-known charge inversion phenomenon $[97,108,109,114]$ - previously shown to influence electro-osmotic flow in nano-channels [40], nanoparticle aggregation [115,116], and electrophoretic mobility [19] — is thought to result from the ion-ion correlations that are neglected in modified Gouy-Chapman theory $[20,21,34]$. We infer that the charge inversion shown in Fig. 8 is intimately related to the formation of metal-choride ion pairs at the surface discussed in the previous section. Evidently, these ion pairs enhance the stability of cationic OSSCs to the point where they locally overcompensate the negative structural charge. A corollary of this is that the magnitude of charge inversion should be quite sensitive to the strength of metal-chloride ion pairs, a property that is notoriously difficult to accurately predict using MD simulations [92]. Therefore, caution should be taken in attaching significance to results such as the ionic strength at which charge inversion occurs in our MD simulations.

\subsection{Three dimensional structure of the electrical double layer}

On flat charged surfaces, EDL models generally assume that ISSC and OSSC occupy discrete adsorption sites whereas DS species are uniformly distributed along directions parallel to the interface. This conceptual view would be quite arduous to verify experimentally but it can be readily tested using MD simulation. In Figs. 9-10, we report the average densities of $\mathrm{Na}^{+}, \mathrm{Ca}^{2+}$, and $\mathrm{Cl}^{-}$(first, second, and third rows, respectively) in the $x y$ plane at four distances from one of the clay basal surfaces in our simulation cell (from left to right columns: ISSC, OSSC, DS, and DS2 coordinates) and at two ionic strengths (0.34 and $1.83 \mathrm{~mol}_{\mathrm{c}} \mathrm{dm}^{-3}$ in Figs. 9 and 10, respectively). Similar results were obtained on the opposite surface and at intermediate ionic strengths.

Our results show that the clay structure influences ion distribution in the $x y$ plane on two spatial scales: the siloxane surface (the plane of $O$ atoms that forms the clay surface) influences ion distribution on scales of Ångströms, whereas the distribution of negative charge sites (isomorphic substitutions of $\mathrm{Al}$ by $\mathrm{Mg}$ in the octahedral sheet) influences ion distribution on scales of nanometers. The first phenomenon is observed only for cationic surface complexes. Thus, $\mathrm{Na}^{+}$ISSCs are located preferentially directly above individual $\mathrm{O}$ atoms of the siloxane surface (Figs. 9a, 10a), as also found for kaolinite [117]. This 
finding, along with the water density map near $\mathrm{Na}^{+}$ISSC in Fig. $5 \mathrm{~d}$, indicates that $\mathrm{Na}^{+}$ ISSC formation involves the replacement of one water molecule by one surface $\mathrm{O}$ atom in the first solvation shell of $\mathrm{Na}^{+}$, as also shown by Dufrêche et al. [41]. Figures 9-10 also reveal that $\mathrm{Na}^{+}$and $\mathrm{Ca}^{2+}$ OSSCs are preferentially located above two features of the siloxane surface: hexagonal (more precisely: ditrigonal) cavities and "triads" of surface $\mathrm{O}$ atoms bound to the same $\mathrm{Si}$ atom (Figs. 9b,e, 10b,e). Clearly, $\mathrm{Ca}^{2+}$ OSSCs prefer the former (ditrigonal cavity) site, as also found for $\mathrm{Cd}^{2+}$ and $\mathrm{Pb}^{2+}$ on the siloxane surface of kaolinite [117]. These two sites allow either six or three surface $\mathrm{O}$ atoms to participate in the second cationic solvation shell. Our results reveal no discernible influence of the siloxane surface on the distribution of DS species, whereas $\mathrm{Cl}^{-}$OSSCs were too scarce to identify their preferred locations precisely on the siloxane surface.

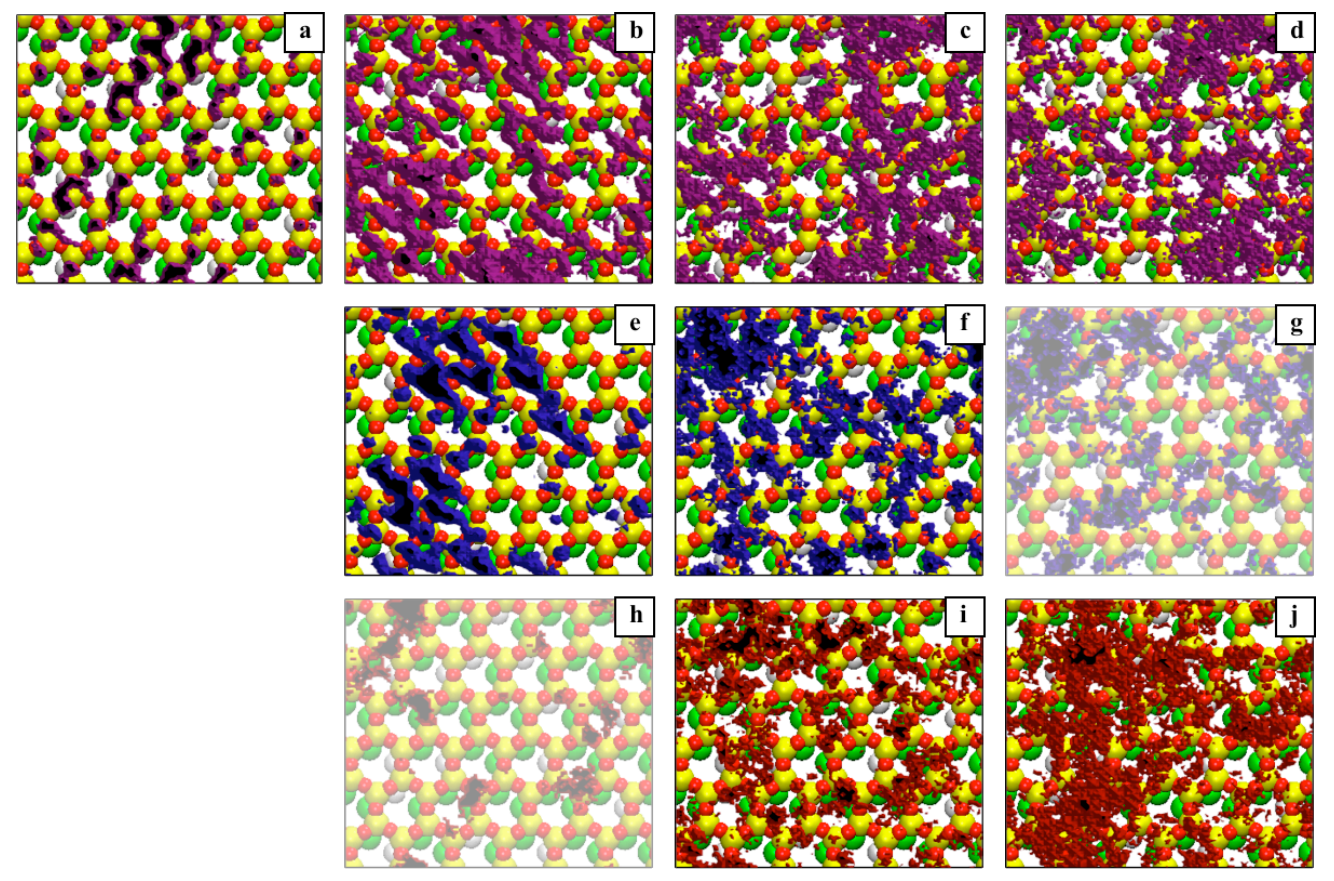

Figure 9. Average densities of $\mathrm{Na}^{+}, \mathrm{Ca}^{2+}$, and $\mathrm{Cl}^{-}$(first, second, and third rows) at different distances from one of the clay surfaces (ISSC, OSSC, DS, and DS2 coordinates in the first through the fourth columns) in our MD simulation at $0.34 \mathrm{~mol}_{\mathrm{c}} \mathrm{dm}^{-3}$. Ion densities in the $x y$ plane are reported relative to the average density of the same species over both clay surfaces at the same $z$ coordinate [densities lower than the average density are not shown; densities equal to one to three times the average density are shown in purple $\left(\mathrm{Na}^{+}\right)$, blue $\left(\mathrm{Ca}^{2+}\right)$, or ochre $\left(\mathrm{Cl}^{-}\right)$; densities equal to more than three times the average density at the same $z$ coordinate are shown in black]. Coordinates of $\mathrm{Si}$ and $\mathrm{O}$ atoms in the underlying siloxane surface and of $\mathrm{Al}$ and $\mathrm{Mg}$ atoms in the 
octahedral sheet are shown with the same colors as in Fig. 2. Shaded figures $(9 \mathrm{~g}, \mathrm{~h})$ indicate poor statistics.
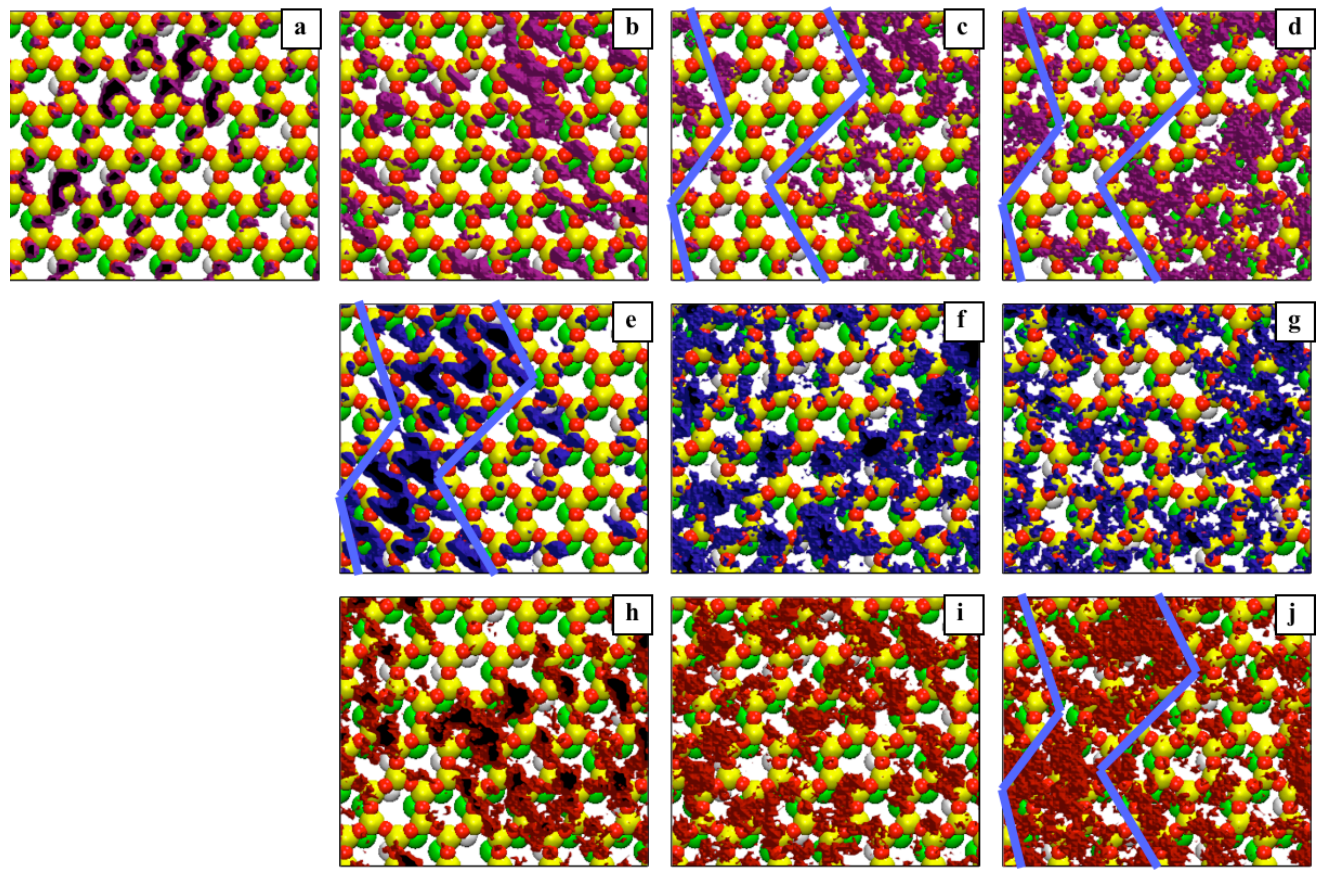

Figure 10. Same as Fig. 9 at $1.83 \mathrm{~mol}_{\mathrm{c}} \mathrm{dm}^{-3}$.

In the view of the surface shown in Figs. 9-10, the density of isomorphic substitutions in the octahedral sheet is greater on the left side of each figure. The influence of this asymmetric charge density distribution on the three-dimensional structure of the EDL is evident in the greater density of $\mathrm{Na}^{+}$ISSCs (Figs. 9a and 10a) and especially $\mathrm{Ca}^{2+}$ OSSCs (Figs. 9e and 10e) on the left side of the surface (region delineated by thick blue lines in Fig. 10e). The $\mathrm{Cl}^{-} \mathrm{DS} 2$ species is preferentially located in this region (Figs. 9j and 10j), thus confirming that the $\mathrm{Cl}^{-}$DS2 peak reflects $\mathrm{Cl}^{-}$association with $\mathrm{Ca}^{2+}$ OSSCs, whereas $\mathrm{Na}^{+}$adsorption in the diffuse swarm is inhibited in this region (Figs. 9c,d and 10c,d), reflecting the charge inversion phenomenon discussed in the previous section. Thus, our results indicate that charge inversion does not occur uniformly on the clay surface. Instead, nanometer-scale regions of conventional (counterion-rich) and "charge-inverted" (coion-rich) diffuse swarms co-exist. This "patchy" charge inversion contradicts the assumption that EDL ions are uniformly distributed in the $x y$ plane beyond the d-plane, at least at the high ionic strengths studied here. We hypothesize that this patchiness of the 
EDL could promote the adsorption of molecules that carry different types of functional group, such as those in natural organic matter [118] or, more generally, zwitterions [119].

\section{Diffusion in the Electrical Double Layer}

Water and solute diffusion coefficients near solid-water interfaces are fundamental parameters that influence solute mass fluxes in nanoporous media, such as natural or engineered clay barriers [54], the electrophoretic mobility of nanoparticles [11], and the rates of transport-limited interfacial reactions [120]. At the molecular level, the diffusion coefficient can be calculated using the well-known Einstein relation [121]:

$$
D=\frac{1}{2 n} \lim _{\tau \rightarrow \infty} \frac{d\left\langle\ell^{2}\right\rangle}{d \tau}
$$

where $\left\langle\ell^{2}\right\rangle=\left\langle|\mathbf{r}(t)-\mathbf{r}(t+\tau)|^{2}\right\rangle$ is the mean-square displacement of a diffusing molecule averaged over all molecules of interest and all time intervals of length $\tau, \mathbf{r}(t)$ denotes the position of a diffusing molecule at time $t$, and $n$ is the dimensionality of the system in which diffusion occurs. Near flat surfaces, $D$ becomes a diagonal tensor $\mathbf{D}(\mathbf{z})$ with components $D_{\|}(z)$ and $D_{\star}(z)$ in directions parallel and normal to the interface $[44,50,121]$. Calculation of $D_{\|}(z)$ and $D_{\perp}(z)$ is non-trivial because the infinite-time limit on the integral in Eq. 2 prevents applying this equation at fixed $z$-values [121]. Previous studies have treated this difficulty by calculating $\left\langle\ell_{\| 1}^{2}\right\rangle$ and $\left\langle\ell_{\perp}^{2}\right\rangle$ for given values of $\tau$, then evaluating the slope $\Delta\left\langle\ell_{\| 1}^{2}\right\rangle / \Delta \tau$ for a chosen range of $\tau$-values (e.g., $\tau=0$ to 1.5 ps [51], 1.2 to 2.4 ps [48], 0 to $10 \mathrm{ps}$ [50], or 8 to $16 \mathrm{ps}$ [49]). The choice of this range is not trivial either, however. In recent MD simulations of water and ionic motions in smectite interlayer nanopores (one-, two-, and three-layer hydrates), $d\left\langle\ell_{\| 1}^{2}\right\rangle / d \tau$ did not reach the diffusive limit until $\tau>100 \mathrm{ps}[54]$.

The anisotropy of diffusion near mineral surfaces is illustrated in Fig. 11, which shows the $z$ coordinates and $\Delta x y$ displacements, after time intervals $\tau=1,10,50$ and 200 ps, of water molecules initially located at $z=5.0 \pm 0.2 \AA$, the location of the first shoulder in the water density profile. The density of points in Fig. 11 is related to the van Hove self-correlation function that is probed experimentally by neutron scattering techniques [122]. Figure 11 shows that water molecules initially located at $z=5.0 \AA$ do not diffuse 
parallel to the mineral surface. Instead, they exchange rapidly with water molecules at $z=$ $5.9 \AA$ (i.e., in the first water peak), then they diffuse along the surface or toward the bulk liquid. A small fraction of the water molecules returns to the coordinate $z=5.0 \AA$ after having travelled a distance $\Delta x y=5.0 \pm 0.5 \AA$. This distance is identical to that between neighboring ditrigonal cavities of the siloxane surface $(5.2 \pm 0.1 \AA)$, thus confirming that the water molecules located at $z=5.0 \AA$ are also located above these cavities.
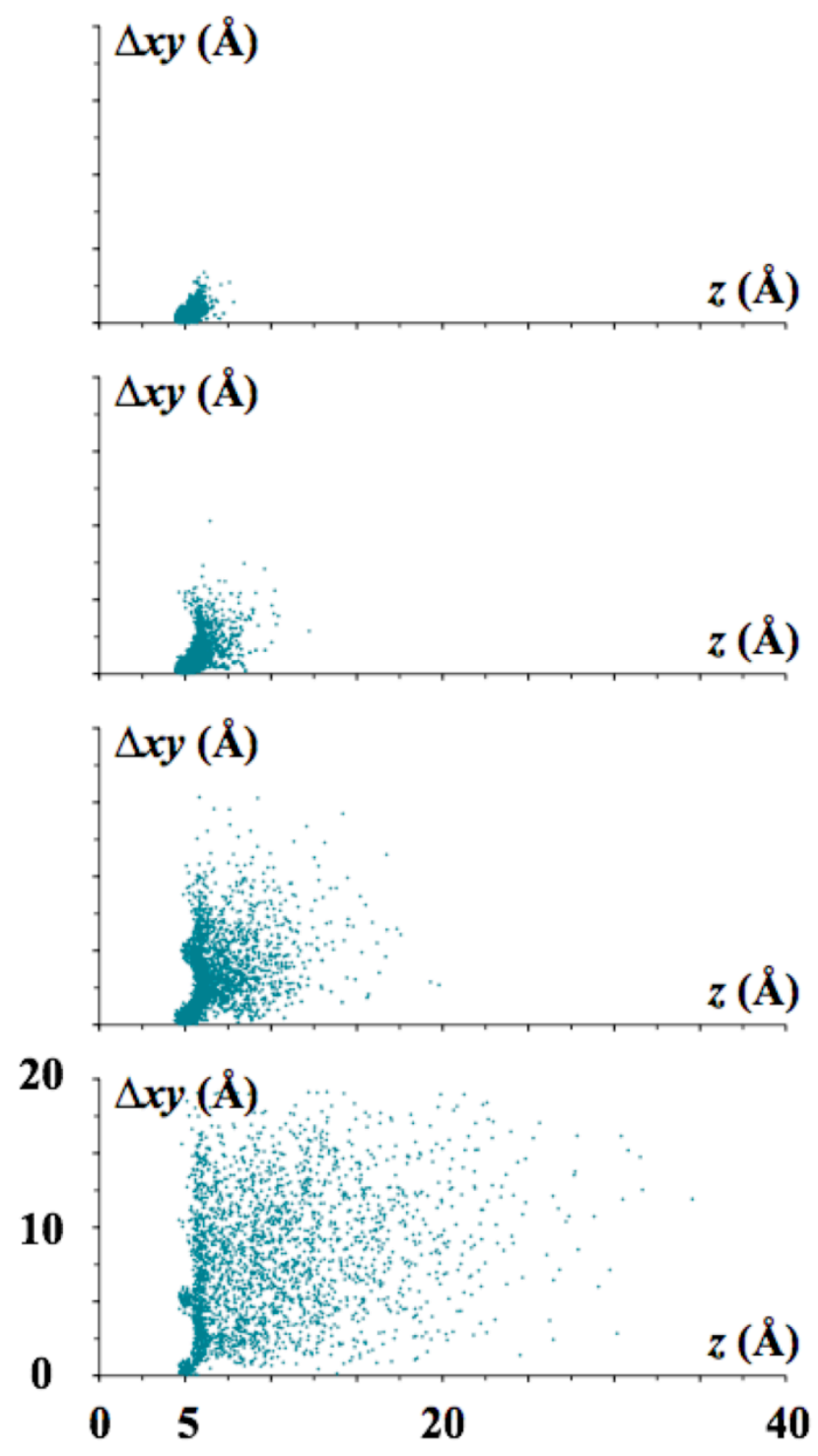

Figure 11. Map of the $\Delta x y$ displacements and final $z$ coordinates, for time intervals $\tau=1,10$, 50 , and $200 \mathrm{ps,} \mathrm{of} \mathrm{all} \mathrm{water} \mathrm{molecules} \mathrm{initially} \mathrm{located} \mathrm{in} \mathrm{the} \mathrm{first} \mathrm{shoulder} \mathrm{of} \mathrm{the} \mathrm{water} \mathrm{density}$ profile $(z=5.0 \pm 0.2 \AA)$ during the first $10 \mathrm{~ns}$ of our simulation at $0.34 \mathrm{~mol}_{\mathrm{c}} \mathrm{dm}^{-3}$. 


\subsection{Diffusion parallel to the surface}

The diffusion coefficient $D_{\|}(z)$ frequently is determined by applying Eq. 2 to the twodimensional ( $x y$ plane) mean-square displacement of molecules that are continuously located in a layer defined by the coordinates $z \pm 1 / 2 \Delta z$ during a chosen time interval $[49,52,121]$. This method pre-supposes that there exists a time interval $\tau$ sufficiently long that the slope $d\left\langle\ell_{\|}^{2}\right\rangle / d \tau$ reaches the diffusive limit, yet sufficiently short that a significant number of molecules is continuously located in the layer of interest. To test this supposition, we applied it to diffusion in $3.2 \AA$-thick water layers chosen to coincide with the statistical water monolayers observed on the surface $(z<7.8 \AA$ for the first monolayer, $z=7.8$ to $11 \AA$ for the second monolayer, and so forth) and in $2.6 \AA$-thick ion layers chosen to coincide with the regions of ISSC, OSSC, and DS adsorption $(z<6.2 \AA$ for ISSC, $z=6.2$ to $8.8 \AA$ for OSSC, and so forth). Plots of $\left\langle\ell_{\| 1}^{2}\right\rangle$ vs. $\tau$ calculated for water molecules continuously present in the same monolayer during any time interval $[t, t$ $+\tau]$ are shown in Fig. 12a for our MD simulation at $0.34 \mathrm{~mol}_{\mathrm{c}} \mathrm{dm}^{-3}$. Values of $D_{\|}$ calculated from the slopes of the curves in Fig. 12a are shown in Fig. 12b for $\tau$-values sufficiently small that $\geq 2 \%$ of water molecules present at time $t$ remained continuously located in the same monolayer until time $t+\tau$ (for larger $\tau$ values, calculated $D_{\|}$values fluctuated widely). Similar results were obtained at other electrolyte concentrations.

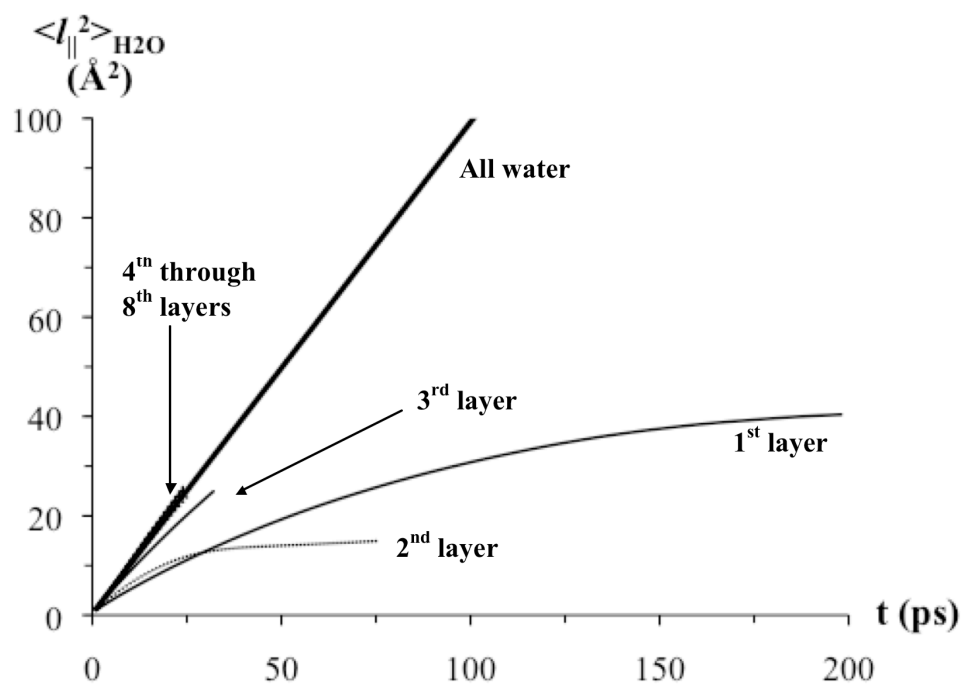




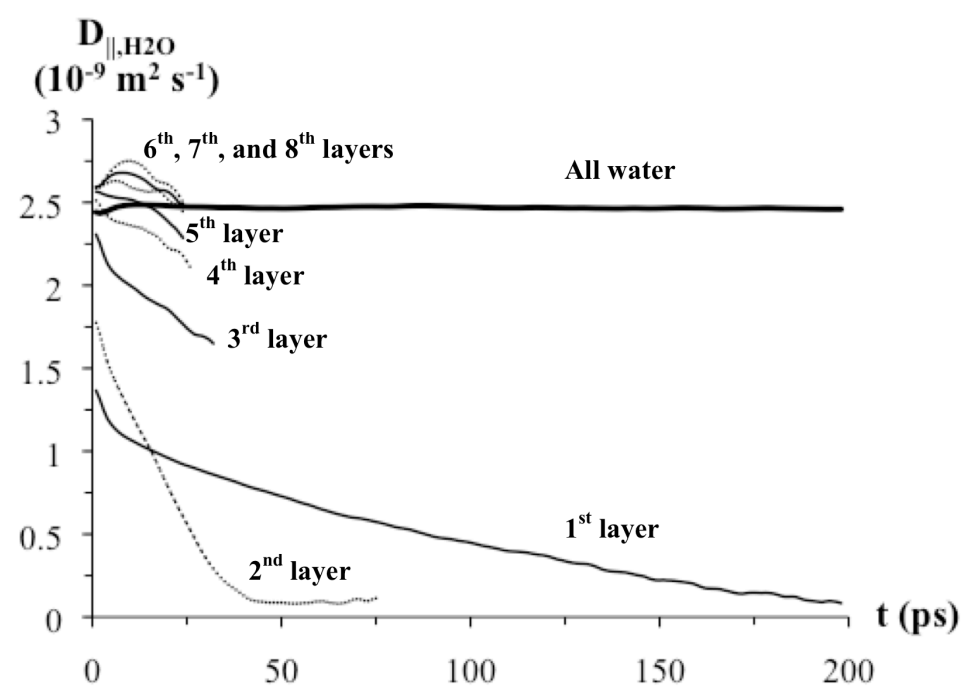

Figure 12. Plots of (a) the mean square displacement $\left\langle\ell_{\| 1}^{2}\right\rangle$ vs. $\tau$ and (b) the diffusion coefficient $D_{\|}$Vs. $\tau$ (calculated from the slope of the curves in Fig. 12a) for water molecules continuously located in the layer of interest during any time interval $[t, t+\tau]$ in our simulation at $0.34 \mathrm{~mol}_{\mathrm{c}} \mathrm{dm}^{-3}$.

Figure $12 \mathrm{~b}$ shows that $D_{\|}$-values can be highly sensitive to the choice of $\tau$; this is a problem, because an optimal $\tau$ is not known [48-51]. In the present study, as a first approximation, we calculated $D_{\|}$as the finite-difference slope $\Delta\left\langle\ell_{\|}^{2}\right\rangle / \Delta \tau$ from $\tau=1$ to 2 ps. This $\tau$-interval was chosen for three reasons. Firstly, for solutes diffusing in bulk liquid water, the mean-square displacement increases linearly for $\tau>1$ ps [90], which indicates that mean-square displacement values obtained for $\tau<1$ ps should not be used to calculate $D_{\|}$. Secondly, for certain solutes in our study, poor statistics caused $D_{\|}$to fluctuate greatly when $\tau>8$ ps (this was the case, for example, for $\mathrm{Ca}^{2+}$ beyond the third layer at $0.34 \mathrm{~mol}_{\mathrm{c}} \mathrm{dm}^{-3}$ ). Thirdly, calculation of $D_{\|}$from the mean-square displacement of molecules that are continuously located in a layer during a time interval $\tau$ implicitly assumes that the probability of a molecule leaving the layer is uncorrelated with its meansquare displacement. This assumption, which appears not to have been noted in previous studies, in fact may not be true; for example, if a water layer contains two populations of water molecules that have unequal diffusion coefficients and that exchange slowly on the timescale of measurement of the mean-square displacement (e.g., water molecules 
solvating divalent metal cations vs. other water molecules $[99,123])$, the more slowlydiffusing water population will be increasingly over-represented at large $\tau$-values. Our hypothesis on the existence of this artifact is consistent with the observation that, at large $\tau$, the $D_{\|}$values for first- and second-monolayer water in Fig. $12 \mathrm{~b}$ tend toward the $D_{\|}$ value of $\mathrm{Ca}^{2+}$ in an $\operatorname{OSSC}\left(0.16 \pm 0.02 \times 10^{-9} \mathrm{~m}^{2} \mathrm{~s}^{-1}\right.$ at $\left.0.34 \mathrm{~mol}_{\mathrm{c}} \mathrm{dm}^{-3}\right)$. We note in passing that the crossover of first- and second-monolayer water curves in Fig. 12b may explain why Marry et al. [49], who calculated $\Delta\left\langle\ell_{\|}^{2}\right\rangle / \Delta \tau$ for $\tau=8$ to $16 \mathrm{ps,} \mathrm{found} \mathrm{that} D_{\|}$ is lowest in the second water monolayer on Na-montmorillonite, whereas Sakuma and

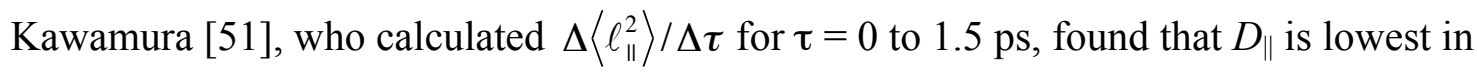
the first water monolayer on mica.

Near mineral surfaces, accurate evaluation of the diffusive limit in Eq. 2 may not be possible with time scales as short as $\tau=1$ to 2 ps. For example, $d\left\langle\ell_{\| 1}^{2}\right\rangle / d \tau$ does not reach its long-time limit until $\tau>100$ ps for water molecules and cations in Na-smectite interlayers (one-, two-, or three-layer hydrates) [54]. To evaluate the importance of this possibility, we calculated $\left\langle\ell_{\|}^{2}\right\rangle$ and $D_{\|}(\tau)$ as a function of $\tau$ for all (i.e., regardless of $z$ coordinate) water molecules, $\mathrm{Na}^{+}, \mathrm{Ca}^{2+}$, or $\mathrm{Cl}^{-}$in our simulation cell (shown for water molecules in Fig. 12). For most species (excepting $\mathrm{Cl}^{-}$at the lowest ionic strength considered, where precision was lowest), our results showed a small decrease in these "overall" $D_{\|}$values with $\tau$. We hypothesize that this decrease results from timescales $<$ 100 ps being too small to probe the long-time limiting value of $d\left\langle\ell_{\|}^{2}\right\rangle / d \tau$ in the first few monolayers near the mineral surface. We calculated how large an adjustment of the $D_{\|^{-}}$ values of first-layer water or of ions in ISSCs or OSSCs would explain the $\tau$-dependence of our "overall" $D_{\|}$values in going from $\tau=1-2 \mathrm{ps}$ to $\tau=198-200 \mathrm{ps}$. To minimize random error, we averaged the adjustment (after normalization to $D_{\|}$in the bulk liquid) over our simulations at four ionic strengths (for $\mathrm{Cl}^{-}$, we again ignored the results at the lowest ionic strength). Finally, we added the adjustment to the negative error bars of first-monolayer water and of ions in ISSCs (first-layer) and OSSCs (second-layer). We also added half of the adjustment to the negative error bars in the next layer, one quarter in the following layer, and so forth. 

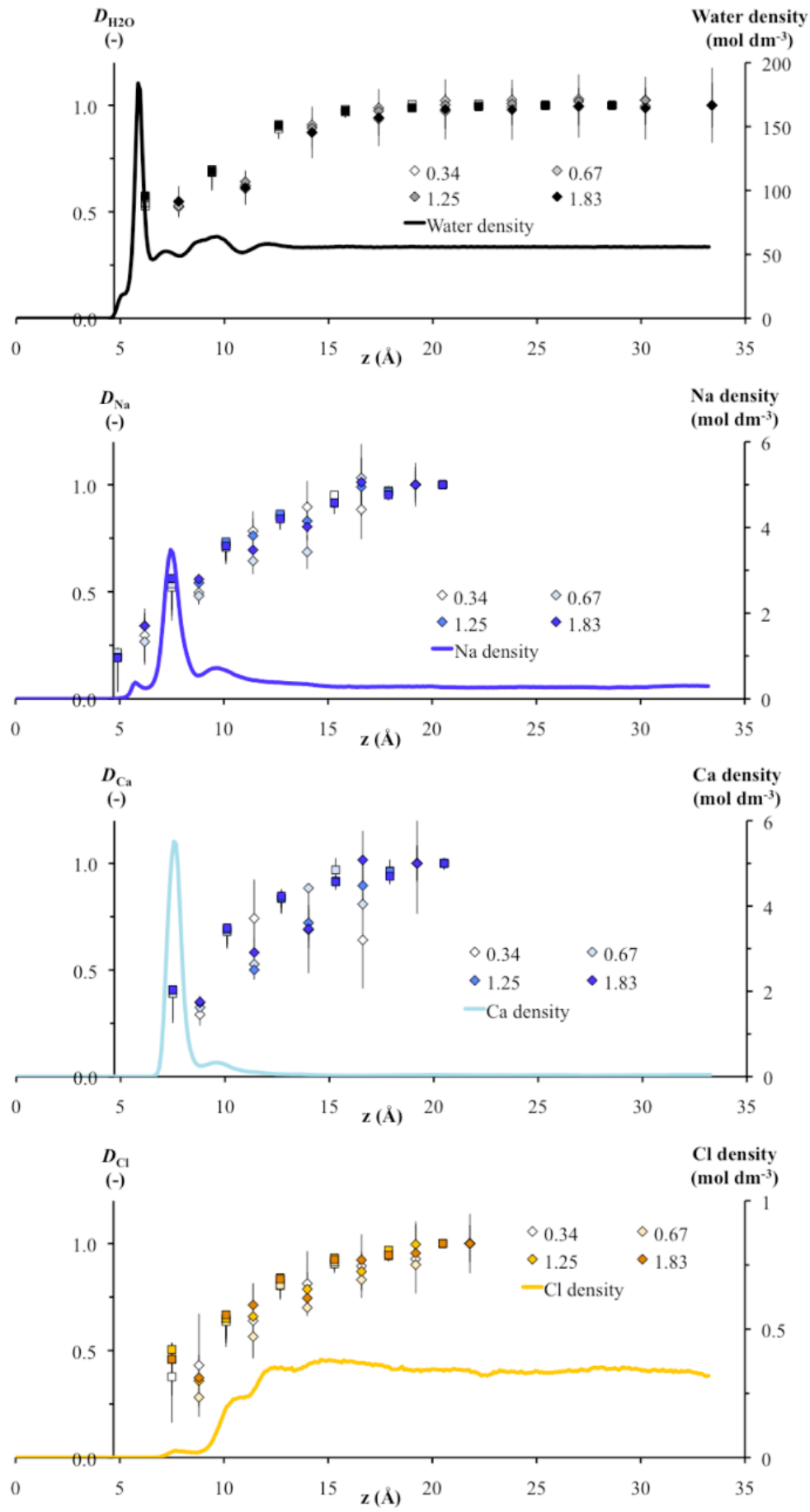

Figure 13. Diffusion coefficients of water, $\mathrm{Na}^{+}, \mathrm{Ca}^{2+}$, and $\mathrm{Cl}^{-}$parallel to the clay surface (square symbols, calculated from the two-dimensional form of Eq. 2) or normal to the clay surface (diamond-shaped symbols, calculated from the average times $\tau_{i-j}$ for jumps between adjacent layers) plotted as a function of distance from the mid-lamella plane. 
We report $D_{\|}$values for water and ions as a function of distance from the surface (normalized to $D_{\|}$far from the surface) as square symbols in Fig. 13. Our results show that water and ion diffusion coefficients $D_{\|}$decrease within about $10 \AA$ (three statistical water monolayers) from the surface. Water in the first monolayer diffuses about 40 to 56 $\%$ as fast as it does in the bulk liquid, in agreement with experiments showing that water films confined between mica plates remain relatively fluid-like down to nanometer thicknesses [70] and with MD simulations of electro-osmosis in clay interlayers that show significant hydrodynamic slip at the mineral-water interface [41]. Clearly, even the first statistical water monolayer on the basal surface is not "ice-like" but is "liquid-like", as pointed out elsewhere $[38,70]$. Ions also have relatively large $D_{\|}$values near the surface (Table 4): DS species diffuse about $65 \%$ as fast as ions in the bulk liquid, and OSSCs diffuse roughly $40 \%$ as fast as in the bulk liquid, within about $10 \%$ variation. Sodium ions adsorbed in ISSCs, however, diffuse quite slowly (about $13 \%$ as fast as they do in the bulk liquid), in qualitative agreement with results showing that $\mathrm{Cs}^{+}$ (adsorbed predominantly in ISSCs) diffuses very slowly in Na-smectite interlayers [54].

\subsection{Diffusion normal to the clay surface}

For the component of $\mathbf{D}(\mathbf{z})$ normal to the surface $\left[D_{\perp}(z)\right]$, the infinite-time limit in Eq. 2 cannot be calculated at fixed $z$ [121]. However, the existence of discrete layers of water molecules and ions at the mineral-water interface suggests that a jump-diffusion model may adequately describe molecular motions normal to the surface $[35,49]$. To apply such a model, for each of our four MD simulations we calculated how water molecules and ions initially located in each of the water or solute layers defined in the previous section were distributed after $200 \mathrm{ps}$. We modeled these distributions with a one-dimensional finite-difference jump-diffusion model (spatial step $\Delta z=3.2 \AA$ for water, $2.6 \AA$ for ions; with time step $\Delta t=0.1 \mathrm{ps}$ ) in which a fraction $\Delta t / \tau_{i-j}$ of the molecules in layer $i$ move to layer $j$ during each time step, $\tau_{i-j}(\mathrm{ps})$ being the characteristic time for jumps between layers $i$ and $j$. For water, we imposed the condition $\tau_{i-j}=\tau_{j-i}$ because the average water molecule density was almost the same in all monolayers. For ions, we imposed the condition that $\tau_{i-j} / \tau_{j-i}$ be equal to the ratio of average ion densities in the $j$ th and $i$ th layers at equilibrium. The precision of $\tau_{i-j}$ values for ions beyond the diffuse swarm was rather 
poor; therefore, we imposed the condition that $\tau_{i-j}$, defined as the geometric mean of $\tau_{i-j}$ and $\tau_{j-i}$, be independent of $z$ beyond the $6^{\text {th }}$ (for $\mathrm{Na}^{+}$and $\mathrm{Ca}^{2+}$ ) or the $7^{\text {th }}$ layer $\left(\right.$ for $\mathrm{Cl}^{-}$). Figure 14 compares our MD simulation results at $0.34 \mathrm{~mol}_{\mathrm{c}} \mathrm{dm}^{-3}$ and jump-diffusion model fits of the distribution, after $200 \mathrm{ps,} \mathrm{of} \mathrm{water} \mathrm{molecules} \mathrm{initially} \mathrm{located} \mathrm{in} \mathrm{the} \mathrm{first}$ (Fig. 14a) and fifth water layer (Fig. 14b) and of $\mathrm{Ca}^{2+}$ ions initially located in the second (Fig. 14c) and fifth ion layer (Fig. 14d). Values of $\tau_{1-2}, \tau_{2-3}$, and $\tau_{3-4}$ for $\mathrm{Na}^{+}, \mathrm{Ca}^{2+}$ and $\mathrm{Cl}^{-}$, which can be taken as the residence times of these ions as ISSC, OSSC, and DS species, are shown in Table 4. The residence times of OSSC and DS species increase in the order $\mathrm{Cl}^{-}<\mathrm{Na}^{+}<\mathrm{Ca}^{2+}$, as expected if electrostatic attraction to the surface stabilizes adsorbed species. The long residence time of $\mathrm{Ca}^{2+}$ in OSSCs ( $\left.\tau_{2-3}=838 \pm 66 \mathrm{ps}\right)$ shows how important long simulations (10 ns) are to determine accurately the distribution of divalent ions in the electrical double layer.
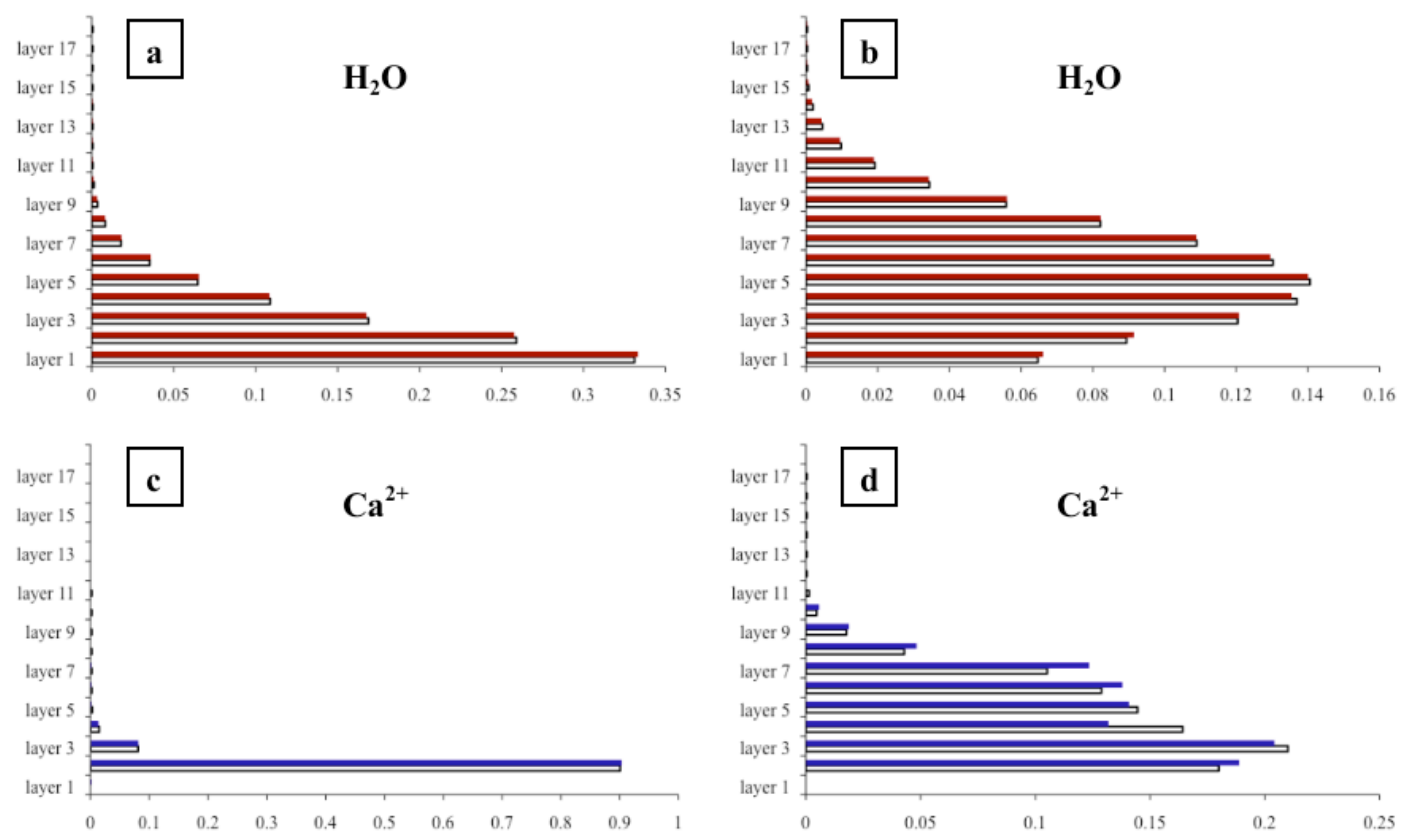

Figure 14. Density distribution after 200 ps, in layers extending away from the clay surface, of water molecules initially located in the first (Fig. 14a) and fifth water layer (Fig. 14b) and of $\mathrm{Ca}^{2+}$ ions initially located in the second (Fig. 14c) and fifth ion layer (Fig. 14d). Filled bars: MD simulation results at $0.34 \mathrm{~mol}_{\mathrm{c}} \mathrm{dm}^{-3}$; open bars: jump-diffusion model fit. 
To compare our results on diffusion normal and parallel to the mineral-water interface, we converted our geometric-mean jump-diffusion times $\tau_{i \curvearrowleft j}$ to apparent diffusion coefficients between layers $i$ and $j$ with a relation analogous to Eq. 2: $D_{\perp}=$ $(\Delta z)^{2} / \tau_{i \sim j}$. The resulting $D_{\perp}$ values are shown in Fig. 13 (diamonds). Confidence intervals were estimated by varying each $D_{\perp}$ value until the root-mean-square deviation between the diffusion model and MD simulation increased by $5 \%$. Within the precision of our calculated $D_{\perp}$ and $D_{\|}$values, we find that the surface has a similar influence on molecular diffusion in directions parallel and normal to the interface (Fig. 13). Comparable profiles of $D_{\|}$and $D_{\perp}$ vs. $z$ have been obtained for water on rutile [48] and feldspar [50] surfaces. Although Spagnoli et al. [124] recently suggested that water molecules diffuse much more rapidly parallel to the surface of hematite nanoparticles than they do normal to the surface, our finding that $D_{\perp} \approx D_{\|}$on smectite surfaces is consistent with previous studies that attributed the slower diffusion of water molecules near these surfaces to participation in the solvation shells of adsorbed cations [98] or to hydrogen bonds formed with surface O atoms [49]. Both of these effects would be expected to decrease $D_{\perp}$ and $D_{\|}$.

\section{Implications for modeling mineral-water interfacial properties}

Here we summarize our findings and their implications concerning the behavior of water and ions in the electrical double layer at clay-water interfaces. Our simulations show that ISSCs, OSSCs, and DS species can coexist in a same nanoscale interfacial region and that "indifferent ions" can form all three types of adsorbed species. The $z$ coordinates of OSSCs (the $\beta$-plane) and of the boundary between OSSCs and DS species (the d-plane) are identical, within imprecision, for $\mathrm{Na}^{+}, \mathrm{Ca}^{2+}$, and $\mathrm{Cl}^{-}\left(z_{\beta}{ }^{*}=4.4 \pm 0.2\right.$ and $\left.z_{\mathrm{d}}{ }^{*}=5.6 \pm 0.3\right)$. This co-occurrence occurs despite the $0.79 \AA$ difference between the crystal radii of $\mathrm{Na}^{+}$and $\mathrm{Cl}^{-}[7]$ and the $1.26 \AA$ difference between the hydrated radii of $\mathrm{Na}^{+}$and $\mathrm{Ca}^{2+}[8]$, thus contradicting attempts to model $z_{\beta}^{*}$ as a fixed (solid-specific) distance plus the hydrated $[8,125]$ or crystalline radius [7] of the adsorbed species. For

smectite basal surfaces, if the 0 -plane is located at $z_{0}{ }^{*}=1.4 \AA$ (one $\mathrm{O}$ atomic radius above the plane of surface $\mathrm{O}$ atoms [52]), the distances between the 0 - and $\beta$-planes and between the $\beta$ - and d-planes are $\Delta z_{1}=3.0 \pm 0.1 \AA$ and $\Delta z_{2}=1.2 \pm 0.1 \AA$, respectively. 
Sodium ISSCs adsorb between the 0 - and $\beta$-planes $\left(z^{*}=2.6 \pm 0.05 \AA\right)$, in disagreement with the tenets of the TLM (Fig. 1) but in agreement with the surface speciation modeling approach of Ridley et al. [6].

Our simulations also yield insight into the capacitances $C_{1}$ and $C_{2}$ of the space between the 0 - and $\beta$-, and $\beta$-and d-planes. By analogy with planar capacitors, these parameters are sometimes modeled with the relation $[4,32]$ :

$$
C_{i}=\varepsilon_{i} \varepsilon_{0} / \Delta z_{i}
$$

where $\varepsilon_{0}=8.854 \times 10^{-12} \mathrm{C}^{2} \mathrm{~J}^{-1} \mathrm{~m}^{-1}$ is the permittivity of vacuum and $\varepsilon_{i}$ is the dielectric constant of water in each "capacitor". The values of $\Delta z_{i}$ and $\varepsilon_{i}$, however, are often poorly constrained. Frequently, $C_{i}$ values are calculated simply by fitting them to experimental data using an assumed model of EDL structure. A widespread strategy in surface speciation calculations consists in assuming that $C_{2}=0.2 \mathrm{~F} \mathrm{~m}^{-2}$ (a value obtained by Yates et al. [3] using the unsupported assumption that $\psi_{\mathrm{d}}$ is equal to the electrokinetic "zeta" potential $[16,31])$ and fitting $C_{1}$ to proton and electrolyte adsorption data using the TLM; this method yields $C_{1}=0.6$ to 2.2 for a range of electrolytes and mineral surfaces [15,31-33,104,125]. Other studies have assumed that $C_{2}=\infty$ (i.e., $\psi_{\mathrm{s}}=\psi_{\mathrm{d}}[107]$ ) or $C_{2}=$ $C_{1}$ [7,126], or have fitted both $C_{1}$ and $C_{2}$ [105,107]. Tournassat et al. [52] estimated that $C_{2}=0.9$ to $1.1 \mathrm{~F} \mathrm{~m}^{-2}$ from their MD simulation results, but they also assumed that $\psi_{\mathrm{d}}$ is equal to the measured electrokinetic "zeta" potential. If we use Eq. 3 with our $\Delta z_{i}$ values given above (hypothesizing that these are invariant at electrolyte concentrations below $0.34 \mathrm{~mol}_{\mathrm{c}} \mathrm{mol}^{-3}$ ) and the dielectric constants predicted by Wander and Clark [113] for the quartz-water interface ( $\varepsilon_{1}=41 \pm 19$ and $\varepsilon_{2}=74 \pm 2$ in the direction normal to the mineral-water interface, to which we assigned confidence intervals equal to half the difference between these values and the dielectric constant of bulk water, 78.3 at $298 \mathrm{~K}$ ), we predict $C_{1}=1.2 \pm 0.6 \mathrm{~F} \mathrm{~m}^{-2}$ and $C_{2}=5.5 \pm 0.1 \mathrm{~F} \mathrm{~m}^{-2}$ for dilute aqueous solutions on smectite basal surfaces. If we use a looser definition of the $\beta$-plane coordinate (allowing this plane to be located anywhere between the DS peak of cations and the minimum between the OSSC and DS peaks, i.e., $\Delta z_{2}=1.6 \pm 0.5 \AA$ ) and account for the possibility that the electric field near the charged surface may influence the dielectric constant of water ( $\varepsilon_{1}$ may be as low as $\sim 10$ at the electric field strength that exists near the smectite clay surface according to the calculations of Danielewicz-Ferchmin and Fermchmin 
[127]), we predict a similar range of capacitance values: $C_{1}=0.8 \pm 0.5 \mathrm{~F} \mathrm{~m}^{-2}$ and $C_{2}=4.1$ $\pm 1.3 \mathrm{~F} \mathrm{~m}^{-2}$. Thus, regardless of the assumptions chosen, our results strongly suggest that $C_{2}$ is larger than $C_{1}$, and much larger than the frequently-used value, $0.2 \mathrm{~F} \mathrm{~m}^{-2}$.

Regarding the influence of brine concentration on the aqueous geochemistry of mineral-water interfaces, we find that the coordinates of adsorbed ISSCs, OSSCs, and DS species are independent of ionic strength. We also find that charge inversion occurs in the diffuse swarm at all electrolyte concentrations studied, in agreement with statistical mechanical theories $[20,21,109,110]$. Therefore, properties that arise from long-range electrostatics at interfaces (such as electrophoresis, electroosmosis, co-ion exclusion, or colloidal aggregation) should not be correctly predicted by the TLM or other EDL models (according to which the electrostatic potential decreases monotonically with distance from the surface when only indifferent electrolyte ions are present) at ion concentrations $\geq 0.34 \mathrm{~mol}_{\mathrm{c}} \mathrm{dm}^{-3}$. This charge inversion phenomenon results from the affinity of the clay surface for metal-chloride ion pairs. Finally, we find that co-ion exclusion, which is neglected by most surface speciation models, balances a large part of the mineral surface charge in concentrated ionic solutions ( $42 \%$ at $1.83 \mathrm{~mol}_{\mathrm{c}} \mathrm{dm}^{-3}$, Table 3). An interesting consequence of this finding is that clay-water interfacial tension should first decrease (when $q$ - is negligible), then stabilize or even increase with ionic strength (when $q$ - becomes large), because of the well-known relationship between Gibbs surface excess $n_{i}{ }^{(\mathrm{w})}$ and interfacial tension $\gamma\left(d \gamma=-\Sigma n_{i}{ }^{(\mathrm{w})} d \mu_{i}\right.$, where $\mu_{i}$ is the chemical potential of solute $i$ and the sum is over all solutes [128]). This hypothesis is qualitatively consistent with measured water- $\mathrm{CO}_{2}$ wetting angles on mica, which show increased wetting of the basal surface by water between 0.01 and $0.1 \mathrm{M} \mathrm{NaCl}$, then decreased wetting by water between 0.1 and $1.0 \mathrm{M} \mathrm{NaCl}$ [129].

On the diffusion of water and ions near clay surfaces, our simulation results show that $\mathrm{Na}^{+}$ISSCs diffuse about $13 \%$ as fast as in bulk liquid water, whereas OSSCs and firstlayer water molecules diffuse 40 to $55 \%$ as fast as in the bulk liquid. Diffusion coefficients reach their bulk liquid values within about $10 \AA$ from the clay surface. Calculated trends in $D$ vs. distance from the surface, when normalized to $D$ in bulk liquid water, are independent of ionic strength and direction (parallel or normal to the clay 
surface), within imprecision, and are only weakly dependent on the type of species (Fig. 13).

Finally, we should reiterate the sensitivity of MD simulation results to the choice of interatomic potential parameters. In the present study, we used a set of ion-water interatomic potentials that correctly describe the coordination structures and diffusion coefficients of water and ions in ambient liquid water and the static dielectric constant of liquid water [85,88-90]. Our clay-water and clay-ion interaction were successfully tested against experimental data on the structure and dynamics of water and ions in smectite interlayer nanopores $[54,130]$. The concurrence of our simulation results with experimental data, theoretical calculations, and previous MD simulation studies, described throughout this paper, suggests that our results are quite robust. However, specific results on the height of water density peaks near the clay surface, on the relative height of the density peaks of OSSC, ISSC, and DL species, and on the strength of metalchloride ion pairs should be taken with caution, as these properties are notoriously difficult to accurately predict using MD simulations.

\section{Acknowledgements}

This research was performed under the auspices of the Center for Nanoscale Control of Geologic $\mathrm{CO}_{2}$, an Energy Frontier Research Center funded by the U.S. Department of Energy, Office of Science, Office of Basic Energy Sciences under Award Number DEAC02-05CH11231. It used resources of the National Energy Research Scientific Computing Center, which is supported by the Office of Science of the U.S. Department of Energy under contract No. DE-AC02-05CH11231. Data interpretation benefitted from discussions between the first author and Alejandro Fernández-Martínez (LBNL) and Laura Nielsen (UC Berkeley).

\section{References}

[1] Sposito G., The Surface Chemistry of Natural Particles, Oxford University Press, Oxford, 2004.

[2] Sposito G., Skipper N.T., Sutton R., Park S.H., Soper A.K., Greathouse J.A., Proc. Natl. Acad. Sci. USA 96 (1999) 3358. 
[3] Yates D.E., Levine S., Healy T.W., J. Chem. Soc. Faraday Trans. I 70 (1974) 1807.

[4] Davis J.A., James R.O., Leckie J.O., J. Colloid Interface Sci. 63 (1978) 480.

[5] Hayes K.F., Leckie J.O., J. Colloid Interface Sci. 115 (1987) 564.

[6] Ridley M.K., Hiemstra T., Van Riemsdijk W.H., Machesky M.L., Geochim. Cosmochim. Acta 73 (2009) 1841.

[7] Sverjensky D.A., Geochim. Cosmochim. Acta 69 (2005) 225.

[8] Sverjensky D.A., Geochim. Cosmochim. Acta 65 (2001) 3643.

[9] Gonçalvès J., Rousseau-Gueutin P., Revil A., J. Colloid Interface Sci. 316 (2007) 92.

[10] Malin J.N., Holland J.G., Geiger F.M., J. Phys. Chem. C 113 (2009) 17795.

[11] Leroy P., Tournassat C., Bizi M., J. Colloid Interface Sci. 356 (2011) 442.

[12] Pashley R.M., J. Colloid Interface Sci. 83 (1981) 531.

[13] Venema P., Hiemstra T., van Riemdijk W.H., J. Colloid Interface Sci. 181 (1996) 45.

[14] McBride M.B., Clays Clay Miner. 45 (1997) 598.

[15] Robertson A.P., Leckie J.O., J. Colloid Interface Sci. 188 (1997) 444.

[16] Lützenkirchen J., J. Colloid Interface Sci. 204 (1998) 119.

[17] Qiao R., Aluru N.R., Colloids Surf. A 267 (2005) 103.

[18] Marry V., Dufreche J.F., Jardat M., Meriguet G., Turq P., Grun F., Colloids Surf. A 222 (2003) 147.

[19] Quesada-Pérez M., González-Tovar E., Martín-Molina A., Lozada-Cassou M., Hidalgo-Álvarez R., Colloids Surf. A 267 (2005) 24.

[20] Kjellander R. J., Phys.: Condens. Matter 21 (2009) 424101.

[21] Henderson D., Boda D., Phys. Chem. Chem. Phys. 11 (2009) 3822.

[22] Weiss C.A., Jr., Kirkpatrick R.J., Altaner S.P., Geochim. Cosmochim. Acta 54 (1990) 1655.

[23] Kim Y., Kirkpatrick R.J., Amer. Mineral. 83 (1998) 661.

[24] Papelis C., Hayes K.F., Colloids Surf. 107 (1996) 89.

[25] Strawn D.G., Sparks D.L., J. Colloid Interface Sci. 216 (1999) 257.

[26] Park C., Fenter P.A., Nagy K.L., Sturchio N.C., Phys. Rev. Lett. 97 (2006) 016101.

[27] Lee S.S., Fenter P.A., Park C., Sturchio N.C., Nagy K.L., Langmuir 26 (2010) 16647.

[28] Catalano J.G., Park C., Fenter P., Zhang Z., Geochim. Cosmochim. Acta 72 (2008) 1986.

[29] Fenter P., Park C., Sturchio N.C., Geochim. Cosmochim. Acta 72 (2008) 1848.

[30] Cheng L., Fenter P., Nagy K.L., Schlegel M.L., Sturchio N.C., Phys. Rev. Lett. 87 (2001) 156103.

[31] Charmas R., Piasecki W., Rudzinski W., Langmuir 11 (1995) 3199.

[32] Sahai N., Sverjensky D.A., Geochim. Cosmochim. Acta 61 (1997) 2827.

[33] Katz L.E., Hayes K.F., J. Colloid Interface Sci. 170 (1995) 477.

[34] Wernersson E., Kjellander R., Lyklema J., J. Phys. Chem. C 114 (2010) 1849.

[35] Chang F.-R.C., Skipper N.T., Sposito G., Langmuir 13 (1997) 2074.

[36] Crozier P.S., Rowley R.L., Henderson D., J. Chem. Phys. 113 (2000) 9202.

[37] Leote de Carvalho R.J.F., Skipper N.T., J. Chem. Phys. 114 (2001) 3727. 
[38] Park S.-H., Sposito G., Phys. Rev. Lett. 89 (2002) 085501.

[39] Predota M., Zhang Z., Fenter P., Wesolowski D.J., Cummings P.T., J. Phys. Chem. B 108 (2004) 12061.

[40] Qiao R., Aluru N.R., Phys. Rev. Lett. 92 (2004) 198301.

[41] Dufrêche J.F., Marry V., Malikova N., Turq P., J. Mol. Liq. 118 (2005) 145.

[42] Kerisit S., Cooke D.J., Marmier A., Parker S.C., Chem. Commun. 24 (2005) 3027.

[43] Kirkpatrick R.J., Kalinichev A.G., Wang J.W., Mineral. Mag. 69 (2005) 289.

[44] Wang J., Kalinichev A.G., Kirkpatrick R.J., Cygan R.T., J. Phys. Chem. B 109 (2005) 15893.

[45] Greathouse J.A., Cygan R.T., Environ. Sci. Technol. 40 (2006) 3865.

[46] Piana S., Jones F., Gale J.D., J. Am. Chem. Soc. 128 (2006) 13568.

[47] Smith D.E., Wang Y., Chaturvedi A., Whitley H.D., J. Phys. Chem. B 110 (2006) 20046.

[48] Predota M., Cummings P.T., Wesolowski D.J., J. Phys. Chem. C 111 (2007) 3071.

[49] Marry V., Rotenberg B., Turq P., Phys. Chem. Chem. Phys. 10 (2008) 4802.

[50] Kerisit S., Liu C., Environ. Sci. Technol. 43 (2009) 777.

[51] Sakuma H., Kawamura K., Geochim. Cosmochim. Acta 73 (2009) 4100.

[52] Tournassat C., Chapron Y., Leroy P., Bizi M., Boulahya F., J. Colloid Interface Sci. 339 (2009) 533.

[53] Meleshyn A., Geochim. Cosmochim. Acta 74 (2010) 1485.

[54] Bourg I.C., Sposito G., Environ. Sci. Technol. 44 (2010) 2085.

[55] Li H., Teppen B.J., Laird D.A., Johnston C.T., Boyd S.A., Environ. Sci. Technol. 38 (2004) 5393.

[56] Sposito G., The Chemistry of Soils, $2^{\text {nd }}$ ed., Oxford University Press, Oxford, 2008.

[57] Fityus S., Buzzi O., Appl. Clay Sci. 43 (2009) 150.

[58] Morrow C.A., Moore D.E., Lockner D.A., Geophys. Res. Lett. 27 (2000) 815.

[59] Otsuki K., Uduki T., Monzawa N., Tanaka H., Isl. Arc. 14 (2005) 22.

[60] Greenwell H.C., Jones W., Coveney P.V., Stackhouse S., J. Mater. Chem. 16 (2006) 708.

[61] Du Y.J., Hayashi S., Liu S.Y., Environ. Geol. 48 (2005) 1096.

[62] Henning J.T., Evans J.C., Shackelford C.D., J. Geotech. Geoenviron. Eng. 132 (2006) 1243.

[63] Gaucher E.C., Tournassat C., Pearson F.J., Blanc P., Crouzet C., Lerouge C., Altmann S., Geochim. Cosmochim. Acta 73 (2009) 6470.

[64] Appelo C.A.J., Van Loon L.R., Wersin P., Geochim. Cosmochim. Acta 74 (2010) 1201.

[65] Gherardi F., Xu T., Pruess K., Chem. Geol. (2007) 103.

[66] Busch A., Alles S., Gensterblum Y., Prinz D., Dewhurst D.N., Raven M.D., Stanjek H., Krooss B.M., Int. J. Greenhouse Gas Control 2 (2008) 297.

[67] Lamorena R.B., Lee W., Environ. Sci. Technol. 42 (2008) 2753.

[68] Koster van Groos A.F., Guggenheim S., Amer. Mineral. 94 (2009) 372.

[69] Charlet L., Tournassat C., Aquatic Geochem. 11 (2005) 115.

[70] Perkin S., Goldberg R., Chai L., Kampf N., Klein J., Faraday Discuss. 141 (2009) 399. 
[71] Leroy P., Revil A., Altmann S., Tournassat C., Geochim. Cosmochim. Acta 71 (2007) 1087.

[72] Bradbury M.H., Baeyens B., J. Contam. Hydrol. 61 (2003) 329.

[73] Wersin P., Curti E., Appelo C.A.J., Appl. Clay Sci. 26 (2004) 249.

[74] Holland H.D., The Chemistry of the Atmosphere and Oceans, Wiley-Interscience, 1978.

[75] Torres M.E., Wallmann K., Tréhu A.M., Bohrmann G., Borowski W.S., Tomaru H., Earth Planet. Sci. Lett. 226 (2004) 225.

[76] Lapham L.L., Alperin M., Chanton J., Martens C., Marine Chem. 112 (2008) 65.

[77] Dilmore R.M., Allen D.E., McCarthy Jones J.R., Hedges S.W., Soong Y., Environ. Sci. Technol. 42 (2008) 2760.

[78] Cantucci B., Montegrossi G., Vaselli O., Tassi F., Quattrocchi F., Perkins E.H., Chem. Geol. 265 (2009) 181.

[79] Kharaka Y.K., Thordsen J.J., Hovorka S.D., Nance H.S., Cole D.R., Phelphs T.J., Knauss K.G., Appl. Geochem. 24 (2009) 1106.

[80] Refson K., Comput. Phys. Commun. 126 (2000) 310.

[81] Bickmore B.R., Rosso K.M., Nagy K.L., Cygan R.T., Tadanier C.J., Clays Clay Miner. 51 (2003) 359.

[82] Tournassat C., Ferrage E., Poinsignon C., Charlet L., J. Colloid Interface Sci. 273 (2004) 234.

[83] Sainz-Díaz C.I., Cuadros J., Hernández-Laguna A., Phys. Chem. Miner. 28 (2001) 445.

[84] Berendsen H.J.C., Grigera J.R., Straatsma T.P., J. Phys. Chem. 91 (1987) 6269.

[85] Smith D.E., Dang L.X., J. Chem. Phys. 100 (1994) 3735.

[86] Åqvist J., J. Phys. Chem. 94 (1990) 8021.

[87] Cygan R.T., Liang J.-J., Kalinichev A.G., J. Phys. Chem. 108 (2004) 1255.

[88] Hura G., Russo D., Glaeser R.M., Head-Gordon T., Krack M., Parrinello M., Phys. Chem. Chem. Phys. 5 (2003) 1981.

[89] Wasserman E., Wood B., Brodholt J., Geochim. Cosmochim. Acta 59 (1995) 1.

[90] Koneshan S., Rasaiah J.C., Lynden-Bell R.M., Lee S.H., J. Phys. Chem. B 102 (1998) 4193.

[91] Bourg I.C., Richter F.M., Christensen J.N., Sposito G., Geochim. Cosmochim. Acta 74 (2010) 2249.

[92] Joung I.S., Cheatham T.E., III, J. Phys. Chem. B 113 (2009) 13279.

[93] Kumar A., Atkinson G., Howell R.D., J. Solution Chem. 11 (1982) 857.

[94] Toney M.F., Howard J.N., Richer J., Borges G.L., Gordon J.G., Melroy O.R., Wiesler D.G., Yee D., Sorensen L.B., Surf. Sci. 335 (1995) 326.

[95] Schlegel M.L., Nagy K.L., Fenter P., Cheng L., Sturchio N.C., Jacobsen S.D., Geochim. Cosmochim. Acta 70 (2006) 3549.

[96] Bourg I.C., Sposito G., Bourg A.C.M., Clays Clay Miner. 54 (2006) 363.

[97] Torrie G.M., Kusalik P.G., Patey G.N., J. Chem. Phys. 90 (1989) 4513.

[98] Woelki S., Kohler H.-H., Krienke H., J. Phys. Chem. B 112 (2008) 3365.

[99] Sposito G., Prost R., Chem. Rev. 82 (1982) 553.

[100] Sposito G., Soil Sci. Soc. Am. J. 55 (1991) 965.

[101] Griffoen J., Appelo C.A.J., Soil Sci. Soc. Am. J. 57 (1993) 716.

[102] Xu L., Salmeron M., Langmuir 14 (1998) 5841. 
[103] Ferrage E., Tournassat C., Rinnert E., Charlet L., Lanson B., Clays Clay Miner. 53 (2005) 348.

[104] Criscenti L.J., Sverjensky D.A., J. Colloid Interface Sci. 253 (2002) 329.

[105] Boily J.-F., Sjoberg S., Persson P., Geochim. Cosmochim. Acta 69 (2005) 3219.

[106] Sverjensky D.A., Fukushi K., Geochim. Cosmochim. Acta 70 (2006) 3778.

[107] Hiemstra T., Van Riemsdijk W.H., J. Colloid Interface Sci. 301 (2006) 1.

[108] Torrie G.M., Valleau J.P., J. Phys. Chem. 86 (1982) 3251.

[109] Outhwaite C.W., Bhuiyan L.B., J. Chem. Soc., Faraday Trans. 2 (1983) 707.

[110] Attard P., Adv. Chem. Phys. 92 (1996) 1.

[111] Koizumi H., Fujiwara K., Uda S., Cryst. Growth Des., in press.

[112] Teschke O., Ceotto G., de Souza E.F., Phys. Chem. Chem. Phys. 3 (2001) 3761.

[113] Wander M.C.F., Clark A.E., J. Phys. Chem. C 112 (2008) 19986.

[114] Grosberg A.Y., Nguyen T.T., Shklovskii B.I., Rev. Mod. Phys. 74 (2002) 329.

[115] Lyubartsev A.P., Tang J.X., Janmey P.A., Nordenskiöld L., Phys. Rev. Lett. 81 (1998) 5465.

[116] Allahyarov E., Gompper G., Löwen H., J. Phys.: Condens. Matter 17 (2005) S1827.

[117] Vasconcelos I.F., Bunker B.A., Cygan R.T., J. Phys. Chem. C 111 (2007) 6753.

[118] Sutton R., Sposito G., Geochim. Cosmochim. Acta 70 (2006) 3566.

[119] Aristilde L., Marichal C., Miéhé-Brendlé J., Lanson B., Charlet L., Environ. Sci. Technol. 44 (2010) 7839.

[120] Black J.R., John S., Young E.D., Kavner A., Geochim. Cosmochim. Acta 74 (2010) 5187.

[121] Liu P., Harder E., Berne B.J., J. Phys. Chem. B 108 (2004) 6595.

[122] March N.H., Tosi M.P., Atomic Dynamics in Liquids, Dover, New York, 1976.

[123] Sobolev O., Le Forestier L., González M.A., Russina M., Kemner E., Cuello G.J., Charlet L., J. Phys. Chem. C 113 (2009) 13801.

[124] Spagnoli D., Gilbert B., Waychunas G.A., Banfield J.F., Geochim. Cosmochim. Acta 73 (2009) 4023.

[125] Kitamura A., Fujiwara K., Yamamoto T., Nishikawa S., Moriyama H., Nucl. Sci. Technol. 36 (1999) 1167.

[126] Wolthers M., Charlet L., Van Cappellen P., Am. J. Sci. 308 (2008) 905.

[127] Danielewicz-Ferchmin I., Ferchmin A.R., Phys. Chem. Chem. Phys. 6 (2004) 1332.

[128] Butt H.-J., Graf K., Kappl M., Physics and Chemistry of Interfaces, $2^{\text {nd }}$ ed., Wiley$\mathrm{VCH}$, Weinhem, 2006.

[129] Chiquet P., Broseta D., Thibeau S., Geofluids 7 (2007) 112.

[130] Marry V., Dubois E., Malikova N., Durand-Vidal S., Longeville S., Breu J., Environ. Sci. Technol., in review. 
TABLE 1. Short-range interaction potential parameters and atomic partial charges $\left(q_{i}\right)$ used in our MD simulations. Short-range interaction potentials $\left(\phi_{i j}, \mathrm{~kJ} \mathrm{~mol}^{-1}\right)$ were modeled with the Lennard-Jones 6-12 form: $\phi_{i j}=4 \varepsilon_{i j}\left[\left(\sigma_{i j} / r_{i j}\right)^{12}-\left(\sigma_{i j} / r_{i j}\right)^{6}\right]$ where $r_{i j}(\AA)$ is the $i-j$ interatomic distance and $2^{1 / 6} \sigma_{i j}$ and $\varepsilon_{i j}$ are the location $(\AA)$ and depth $\left(\mathrm{kJ} \mathrm{mol}^{-1}\right)$ of the $i-j$ potential well calculated with the Lorentz-Berthelot combining rules $\left[\sigma_{i j}=1 / 2\left(\sigma_{i}+\sigma_{j}\right)\right.$ and $\left.\varepsilon_{i j}=\varepsilon_{i}^{1 / 2} \varepsilon_{j}^{1 / 2}\right]$.

\begin{tabular}{llll}
\hline \hline & $\sigma_{i}(\AA)$ & $\varepsilon_{i}\left(\mathrm{~kJ} \mathrm{~mol}^{-1}\right)$ & $q_{i}(\mathrm{e})$ \\
\hline SPC/E water [84] & & & \\
water O & 3.16556 & 0.65017 & -0.8476 \\
water H & 0.0 & 0.0 & 0.4238
\end{tabular}

Alkali metals and halides [85]

$\begin{array}{llll}\mathrm{Na}^{+} & 2.35000 & 0.54391 & 1.0 \\ \mathrm{Cl}^{-} & 4.40000 & 0.41839 & -1.0\end{array}$

Alkaline earth metals [86]

$\begin{array}{llll}\mathrm{Ca}^{2+} & 2.36084 & 1.88173 & 2.0\end{array}$

CLAYFF mineral [87]

$\begin{array}{llll}\text { clay } \mathrm{O} & 3.16556 & 0.65017 & -1.0500^{\mathrm{a}} \\ \text { clay } \mathrm{H} & 0.0 & 0.0 & 0.4250 \\ \text { clay } \mathrm{Si} & 3.30203 & 7.7005 \times 10^{-6} & 2.1000 \\ \text { clay } \mathrm{Al} & 4.27124 & 5.5638 \times 10^{-6} & 1.5750 \\ \text { clay } \mathrm{Mg} & 5.26432 & 3.7780 \times 10^{-6} & 1.3600\end{array}$

a the absolute value of $q_{\mathrm{O}}$ was lowered by $0.1 \mathrm{e}$ if $\mathrm{O}$ was bound to a clay $\mathrm{H}$ atom and increased by 0.1308 e near $\mathrm{Al} \rightarrow \mathrm{Mg}$ substitutions [87]. 
TABLE 2. Location $z(\AA)$ of each peak of the water and ion density profiles in our simulations. For the ions, the $z$ coordinates of the minima between ISSC, OSSC, and DS peaks are shown in italics. The plane of surface $\mathrm{O}$ atoms has the average coordinate $z=$ $3.2 \AA$. The precision of $z$-values is $\pm 0.05 \AA$ for most features, but roughly $\pm 0.2 \AA$ for the first shoulder of the first water layer, the third water layer, and the $\mathrm{Cl}^{-}$density features. The numbers of molecules per unit cell contributed by each peak, calculated by integrating the density profiles between minima, are shown between parentheses (precision is about \pm 0.1 for water, \pm 0.001 for ions). For comparison, the structural charge density of the clay is $\sigma_{\text {clay }}=-0.444$ e per unit cell on each surface.

\begin{tabular}{|c|c|c|c|c|}
\hline & $0.34 \mathrm{~mol}_{\mathrm{c}} \mathrm{dm}^{-3}$ & $0.67 \mathrm{~mol}_{\mathrm{c}} \mathrm{dm}^{-3}$ & $1.25 \mathrm{~mol}_{\mathrm{c}} \mathrm{dm}^{-3}$ & $1.83 \mathrm{~mol}_{\mathrm{c}} \mathrm{dm}^{-3}$ \\
\hline \multicolumn{5}{|l|}{ Water } \\
\hline $1^{\text {st }}$ layer shoulder & $5.0(\sim 0.2)$ & $5.0(\sim 0.2)$ & $5.0(\sim 0.2)$ & $5.0(\sim 0.2)$ \\
\hline $1^{\text {st }}$ layer peak 1 & $5.9(3.2)$ & $5.9(3.2)$ & $5.9(3.2)$ & $5.9(3.2)$ \\
\hline $1^{\text {st }}$ layer peak 2 & $7.2(1.8)$ & $7.2(1.7)$ & $7.2(1.7)$ & $7.2(1.9)$ \\
\hline $2^{\text {nd }}$ layer & $9.6(4.7)$ & $9.6(4.8)$ & $9.5(4.8)$ & $9.5(4.7)$ \\
\hline $3^{\text {rd }}$ layer & 12.1 & 12.1 & 12.1 & 12.1 \\
\hline \multicolumn{5}{|l|}{ Sodium } \\
\hline ISSC & $5.8(0.007)$ & $5.8(0.006)$ & $5.8(0.008)$ & $5.8(0.007)$ \\
\hline$I S / O S S C \min$ & 6.2 & 6.2 & 6.2 & 6.2 \\
\hline OSSC & $7.5(0.104)$ & $7.5(0.109)$ & $7.5(0.144)$ & $7.5(0.151)$ \\
\hline OSSC/DS min & 8.8 & 8.8 & 8.8 & 8.8 \\
\hline DS & 9.7 & 9.7 & 9.6 & 9.7 \\
\hline \multicolumn{5}{|l|}{ Calcium } \\
\hline OSSC & $7.6(0.129)$ & $7.6(0.143)$ & $7.6(0.144)$ & $7.6(0.180)$ \\
\hline OSSC/DS min & 8.9 & 8.9 & 8.8 & 8.9 \\
\hline DS & 9.6 & 9.7 & 9.7 & 9.7 \\
\hline \multicolumn{5}{|l|}{ Chloride } \\
\hline OSSC & $7.7(0.001)$ & $7.8(0.002)$ & $7.7(0.008)$ & $7.8(0.018)$ \\
\hline OSSC/DS1 min & 8.7 & 8.5 & 8.6 & 8.6 \\
\hline DS1 & 10.8 & 10.5 & 10.4 & 10.4 \\
\hline DS2 & 12.6 & 12.4 & 12.1 & 12.1 \\
\hline DS3 & 14.9 & 14.4 & 14.1 & 13.8 \\
\hline
\end{tabular}


TABLE 3. Mole fraction in the bulk liquid $\left(x_{i}\right)$ and Gibbs surface excess relative to water $\left(n_{i}^{(\text {w) }}\right.$, molecules per unit cell on each surface [1]) of $\mathrm{Na}^{+}, \mathrm{Ca}^{2+}$ and $\mathrm{Cl}^{-}$in our simulations at aqueous concentrations of $0.34,0.67,1.25$ and $1.83 \mathrm{~mol}_{\mathrm{c}} \mathrm{dm}^{-3}$. Numbers in parenthesis show the percentage of clay cation exchange capacity that is balanced by $\mathrm{Na}^{+}$adsorption, $\mathrm{Ca}^{2+}$ adsorption, and $\mathrm{Cl}^{-}$exclusion. Confidence intervals $( \pm 2 \sigma)$ were calculated by dividing our $50 \mathrm{~ns}$ simulation into five 10 ns blocks.

\begin{tabular}{lllll}
\hline \hline & $0.34 \mathrm{~mol}_{\mathrm{c}} \mathrm{dm}^{-3}$ & $0.67 \mathrm{~mol}_{\mathrm{c}} \mathrm{dm}^{-3}$ & $1.25 \mathrm{~mol}_{\mathrm{c}} \mathrm{dm}^{-3}$ & $1.83 \mathrm{~mol}_{\mathrm{c}} \mathrm{dm}^{-3}$ \\
\hline$x_{\mathrm{Na}}$ & $0.0049 \pm 0.0008$ & $0.0083 \pm 0.0006$ & $0.0124 \pm 0.0019$ & $0.0185 \pm 0.0016$ \\
$x_{\mathrm{Ca}}$ & $0.0006 \pm 0.0006$ & $0.0017 \pm 0.0004$ & $0.0048 \pm 0.0010$ & $0.0067 \pm 0.0007$ \\
$x_{\mathrm{Cl}}$ & $0.0060 \pm 0.0005$ & $0.0119 \pm 0.0003$ & $0.0219 \pm 0.0004$ & $0.0318 \pm 0.0002$ \\
$n_{\mathrm{Na}}{ }^{(\mathrm{w})}$ & $0.110 \pm 0.035$ & $0.061 \pm 0.026$ & $0.085 \pm 0.091$ & $0.006 \pm 0.078$ \\
& $(25 \pm 8 \%)$ & $(14 \pm 6 \%)$ & $(19 \pm 20 \%)$ & $(1 \pm 18 \%)$ \\
$n_{\mathrm{Ca}}{ }^{(\mathrm{w})}$ & $0.140 \pm 0.026$ & $0.143 \pm 0.019$ & $0.110 \pm 0.045$ & $0.125 \pm 0.031$ \\
& $(64 \pm 11 \%)$ & $(64 \pm 7 \%)$ & $(50 \pm 21 \%)$ & $(57 \pm 15 \%)$ \\
$n_{\mathrm{Cl}}{ }^{(\mathrm{w})}$ & $-0.049 \pm 0.022$ & $-0.101 \pm 0.012$ & $-0.138 \pm 0.022$ & $-0.183 \pm 0.011$ \\
& $(11 \pm 5 \%)$ & $(23 \pm 3 \%)$ & $(31 \pm 5 \%)$ & $(42 \pm 3 \%)$ \\
\hline \hline
\end{tabular}


TABLE 4. Average values of the diffusion coefficients $D_{\|}$(normalized to $D_{\|}$in the bulk liquid) and lifetimes $\left[\tau_{1-2}, \tau_{2-3}\right.$, and $\tau_{3-4}(\mathrm{ps})$, in parentheses $]$ of $\mathrm{Na}^{+}, \mathrm{Ca}^{2+}$ and $\mathrm{Cl}^{-}$ISSC, OSSC, and DS species in our MD simulations. (Values of $\tau_{i-j}$ calculated from our MD simulations at $0.34 \mathrm{~mol}_{\mathrm{c}} \mathrm{dm}^{-3}$ were neglected as they had a lower precision.)

\begin{tabular}{llll}
\hline \hline & ISSC & OSSC & DS \\
\hline $\mathrm{Na}^{+}$ & $0.04-0.22(55 \pm 2)$ & $0.40-0.56(213 \pm 3)$ & $0.64-0.73(126 \pm 6)$ \\
$\mathrm{Ca}^{2+}$ & & $0.26-0.40(838 \pm 66)$ & $0.60-0.70(357 \pm 26)$ \\
$\mathrm{Cl}^{-}$ & $0.30-0.51(61 \pm 9)$ & $0.54-0.67(70 \pm 7)$ \\
\hline \hline
\end{tabular}




\section{Na-Ca-Cl brine density}

\section{$\rho\left(\mathrm{kg} \mathrm{dm}^{-3}\right)$}

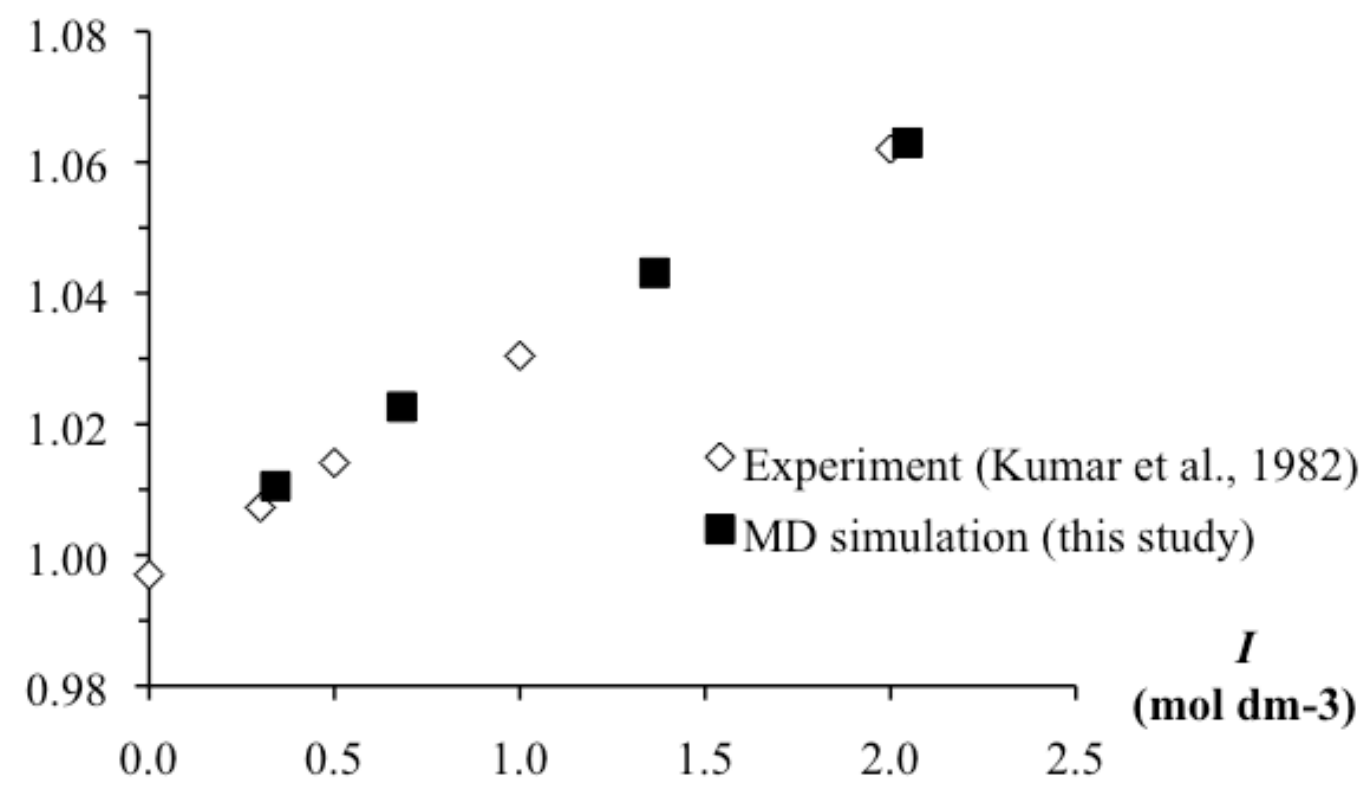

Figure EA1. Experimental and MD simulation results on the densities of $\mathrm{NaCl} / \mathrm{CaCl} \mathrm{C}_{2}$ brines with $\left[\mathrm{Na}^{+}\right]=2 \times\left[\mathrm{Ca}^{2+}\right]$ plotted as a function of ionic strength $I$. Error bars are smaller than symbol sizes. Experimental values were interpolated from experimental data obtained by Kumar et al. (1982) for a range of $\mathrm{Na} / \mathrm{Ca}$ molar ratios. Simulations used $1620 \mathrm{H}_{2} \mathrm{O}$ molecules in a $30.8928 \times 26.9932 \times 60.6 \AA$ periodically replicated simulation cell with $\left[\mathrm{Na}^{+}\right]=2 \times\left[\mathrm{Ca}^{2+}\right]$ and $\left[\mathrm{Cl}^{-}\right]=0.2,0.5,1.0$ or $1.6 \mathrm{~mol} \mathrm{dm}{ }^{-3} ; 200$ ps of equilibration at $298 \mathrm{~K}$ in the $N V E$ ensemble were followed by 400 ps of equilibration at $P_{\mathrm{z}}=0$ atm in the $N P_{z} E$ ensemble (rescaling the velocities of all molecules every 0.1 ps to maintain $T=298 \mathrm{~K}$ ). Predicted brine densities were calculated from the last 300 ps of each simulation. 

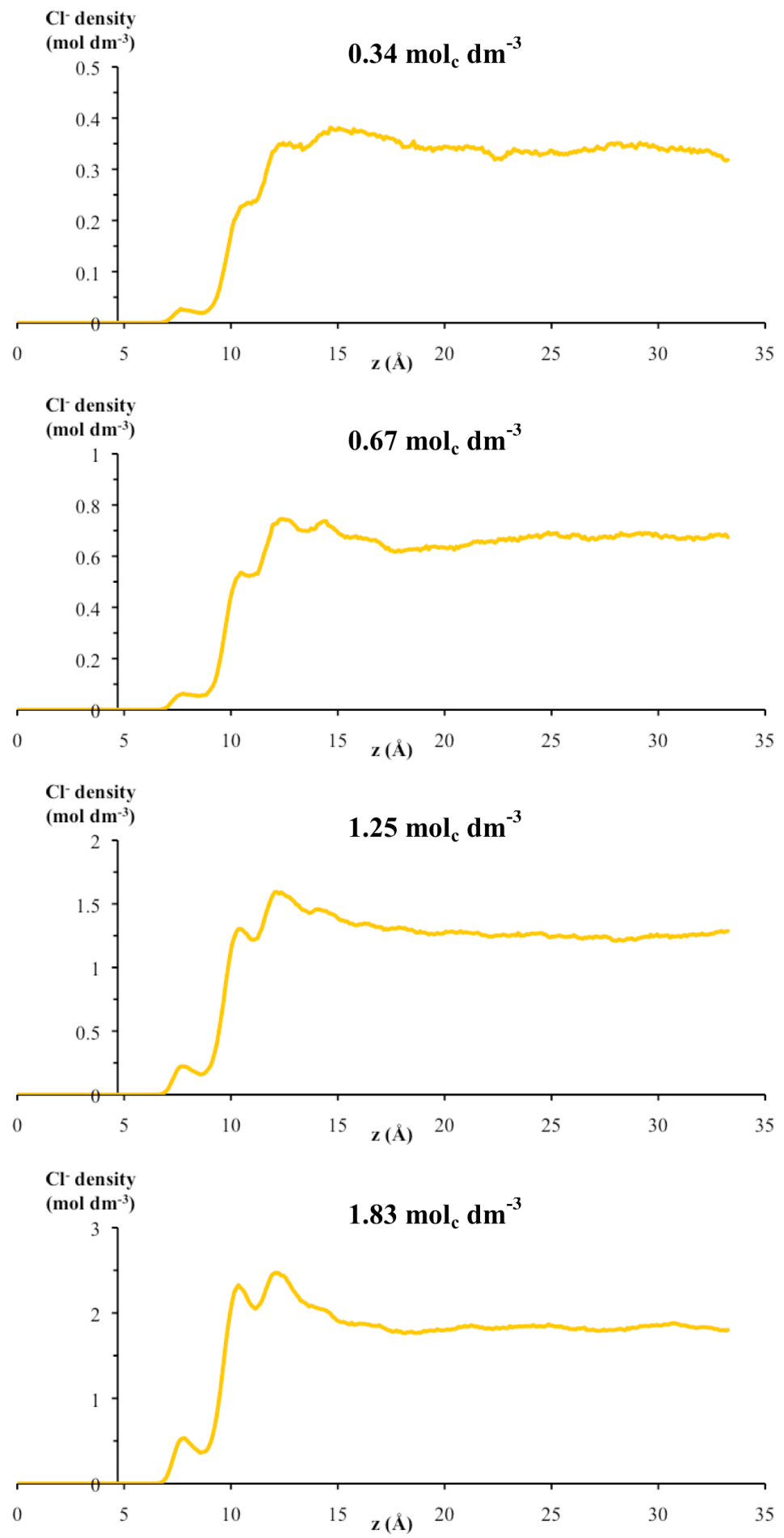

Figure EA2. Detailed view of the chloride concentration profiles in Fig. 3. 


\section{DISCLAIMER}

This document was prepared as an account of work sponsored by the United States Government. While this document is believed to contain correct information, neither the United States Government nor any agency thereof, nor The Regents of the University of California, nor any of their employees, makes any warranty, express or implied, or assumes any legal responsibility for the accuracy, completeness, or usefulness of any information, apparatus, product, or process disclosed, or represents that its use would not infringe privately owned rights. Reference herein to any specific commercial product, process, or service by its trade name, trademark, manufacturer, or otherwise, does not necessarily constitute or imply its endorsement, recommendation, or favoring by the United States Government or any agency thereof, or The Regents of the University of California. The views and opinions of authors expressed herein do not necessarily state or reflect those of the United States Government or any agency thereof or The Regents of the University of California.

Ernest Orlando Lawrence Berkeley National Laboratory is an equal opportunity employer. 